Supporting information and experimental section for:

Consecutive Ribosomal Incorporation of $\alpha$-Aminoxy/ $\alpha-H y d r a z i n o$ Acids with L/D-Configurations into Nascent Peptide Chains

Takayuki Katoh*, Hiroaki Suga*

Department of Chemistry, Graduate School of Science, The University of Tokyo, 7-3-1 Hongo, Bunkyo-ku, Tokyo 113-0033, Japan

*To whom correspondence should be addressed. Tel: +81-3-5841-8372; Fax: +81-3-5841-8372;

E-mail: katoh@chem.s.u-tokyo.ac.jp (T.K.), hsuga@chem.s.u-tokyo.ac.jp (H.S.) 


\begin{tabular}{|c|c|}
\hline \multicolumn{2}{|l|}{ Table of Contents } \\
\hline Supplementary Figure S1. Secondary structures of tRNAs and a microhelix RNA. & $\mathrm{S} 3$ \\
\hline $\begin{array}{l}\text { Supplementary Figure S2. Acylation of } \mu \mathrm{hRNA} \text { using flexizymes analyzed by acid } \\
\text { denaturing PAGE. }\end{array}$ & S4 \\
\hline $\begin{array}{l}\text { Supplementary Figure S3 MALDI-TOF MS of ribosomally synthesized model peptides } \\
\text { containing multiple } \alpha \text {-aminoxy acids or } \alpha \text {-hydrazino acids. }\end{array}$ & S6 \\
\hline $\begin{array}{l}\text { Supplementary Figure S4. De novo sequencing of translated peptides by } \\
\text { MALDI-TOF/TOF MS/MS. }\end{array}$ & S8 \\
\hline $\begin{array}{l}\text { Supplementary Figure S5. Tricine SDS-PAGE analysis of translated peptides P1, P2, P2', } \\
\text { and P2" containing } \alpha \text {-aminoxy or } \alpha \text {-hydrazino acids. }\end{array}$ & S9 \\
\hline $\begin{array}{l}\text { Supplementary Figure S6. Combinations of different } \alpha \text {-aminoxy and } \alpha \text {-hydrazino acids in } \\
\text { consecutive elongation. }\end{array}$ & $\mathrm{S} 10$ \\
\hline $\begin{array}{l}\text { Supplementary Figure S7. }{ }^{1} \mathrm{H} \text { and }{ }^{13} \mathrm{C} \text { NMR spectra of esterified } \alpha \text {-aminoxy and } \\
\alpha \text {-hydrazino acids. }\end{array}$ & $\mathrm{S} 11$ \\
\hline Supplementary Table S1. Conditions of acylation reactions. & $\mathrm{S} 20$ \\
\hline Materials and methods & S21 \\
\hline References for supplementary information & $\mathrm{S} 22$ \\
\hline
\end{tabular}




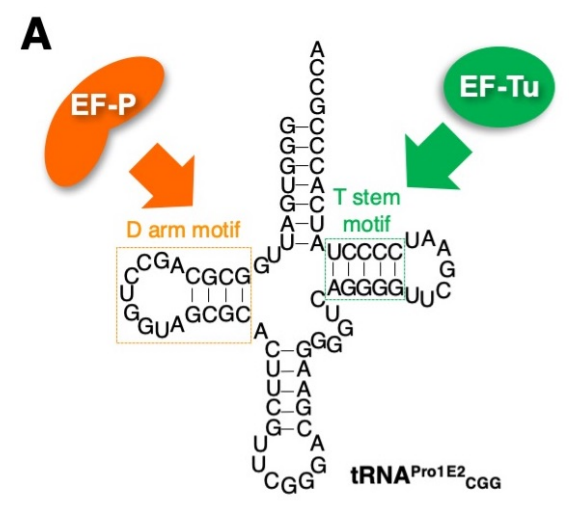

B
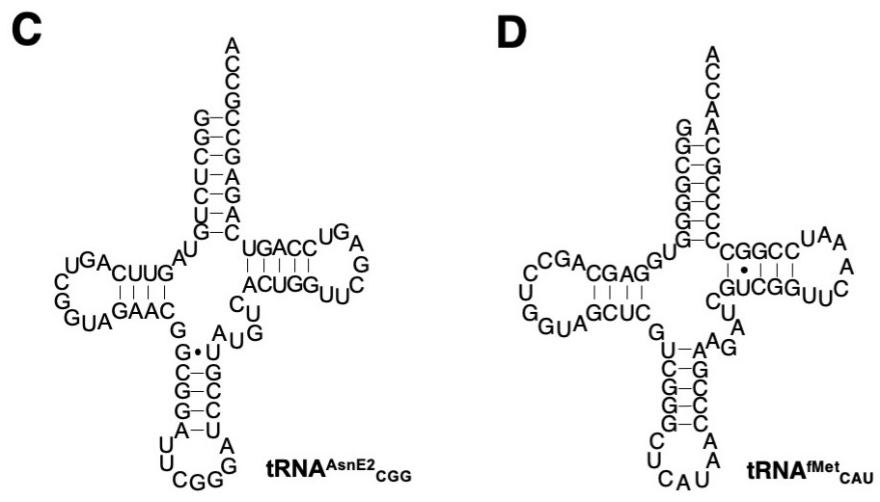

Supplementary Figure S1. Secondary structures of tRNAs and a microhelix RNA. (A) tRNA $^{\text {ProlE2 }}{ }_{\text {CGG }}$ used for decoding CCG codons. The D-arm motif for EF-P binding (a 9-nt D-loop closed with a stable 4-bp stem) is indicated in orange. The T-stem motif for improved EF-Tu binding is indicated in green. The sequence of the anticodon loop is changed accordingly for decoding other codons. See Supplementary Table S2 for the sequences. (B) Secondary structure of a microhelix RNA ( $\mu$ hRNA). (C) tRNA ${ }^{\text {AsnE2 }}$ CGG used for decoding CCG codons. (D) tRNA ${ }^{\text {fMet }}{ }_{\text {CAU }}$ used for incorporation of ${ }^{\mathrm{ClAc}} \mathrm{D}-\mathrm{Tyr}$ at the initiator AUG codon. 
A NoGly

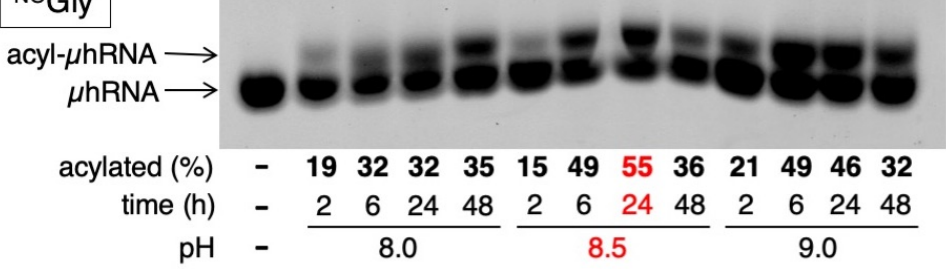

B

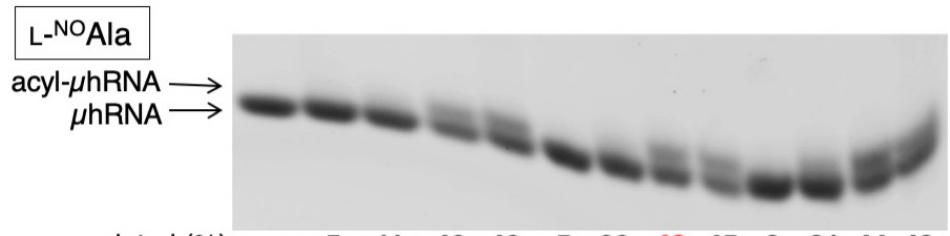

$\begin{array}{llllllllllllll}\text { acylated (\%) } & - & 5 & 11 & 40 & 40 & 5 & 22 & 48 & 45 & 8 & 31 & 44 & 43\end{array}$

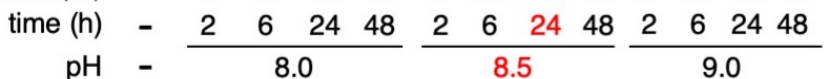

C-NOAla

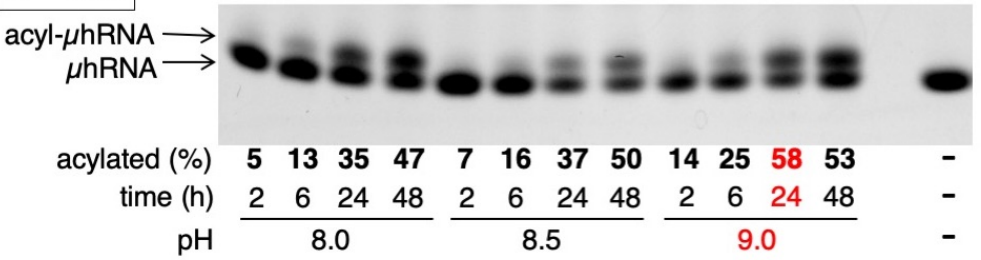

D NAib

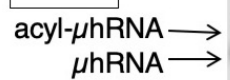

acylated (\%) $\quad-\quad \begin{array}{llllllllllll}2 & 5 & 6 & 11 & 4 & 9 & 13 & 13 & 4 & 13 & 22 & 33\end{array}$

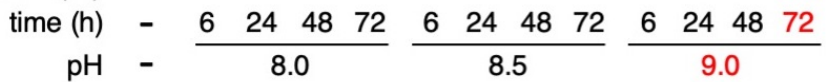

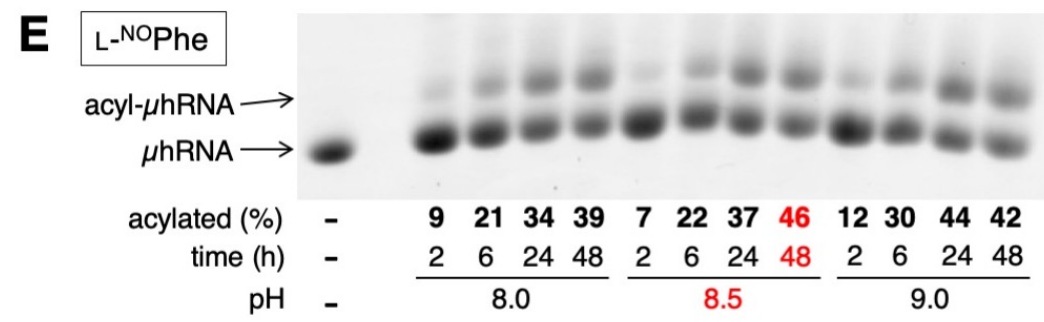

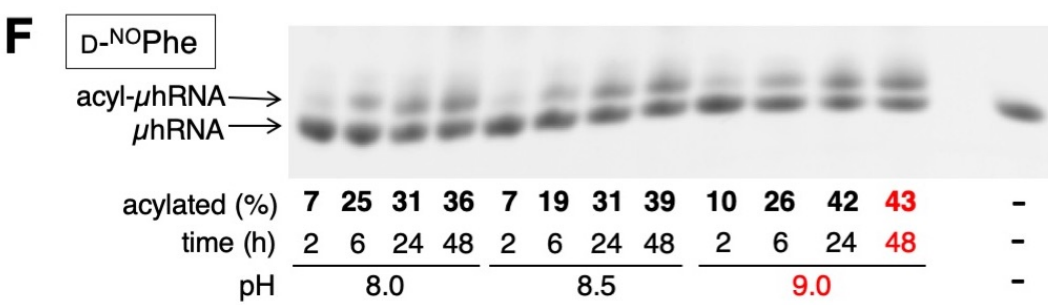

Supplementary Figure S2. Acylation of $\boldsymbol{\mu h R N A}$ using flexizymes analyzed by acid denaturing PAGE. Acylation reactions using ${ }^{\mathrm{NO}}$ Gly-DBE (A), L- ${ }^{\mathrm{NO}}$ Ala-DBE (B), D- ${ }^{\mathrm{NO}}$ Ala-DBE (C), ${ }^{\mathrm{NO}}$ Aib-DBE (D), L- ${ }^{\mathrm{NO}}$ Phe-CME (E), D- ${ }^{\mathrm{NO}}$ Phe-CME (F), ${ }^{\mathrm{NN}} \mathrm{MeGly}-\mathrm{DBE}(\mathrm{G}), \mathrm{L}-{ }^{\mathrm{NN}}$ Pro-DBE (H), and D- ${ }^{\mathrm{NN}} \mathrm{Pro}-\mathrm{DBE}$ (I). Bands were detected by ethidium bromide staining. Arrows indicate positions of desired acyl- $\mu \mathrm{hRNAs}$ and unreacted $\mu \mathrm{hRNAs}$. Red numbers indicate optimal reaction conditions. 

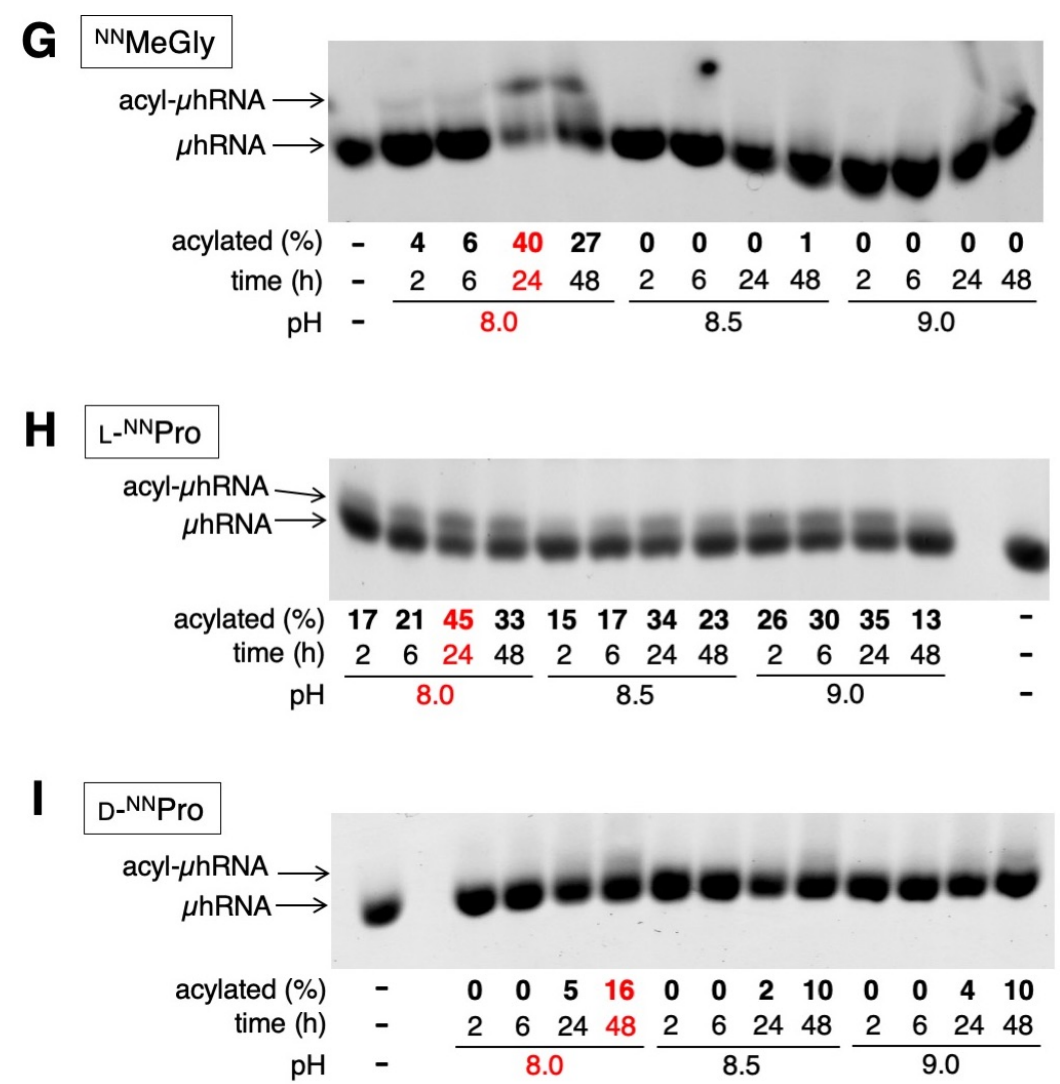

\section{Supplementary Figure S2 continued.}


A
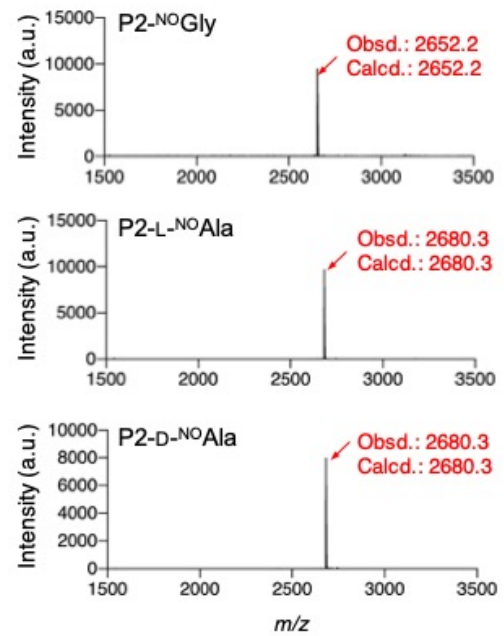
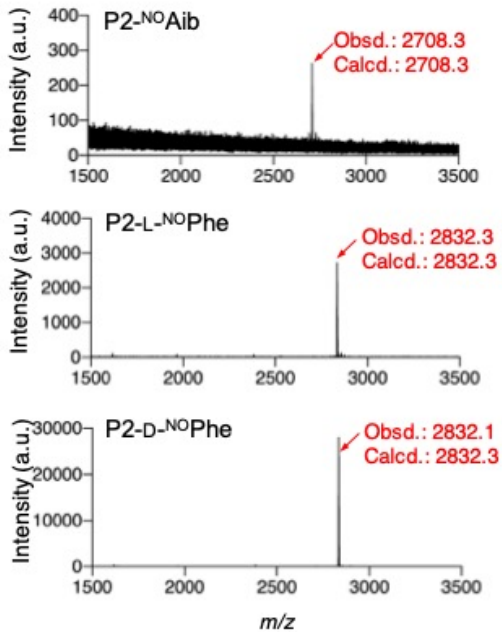

B

Ala misincorporation
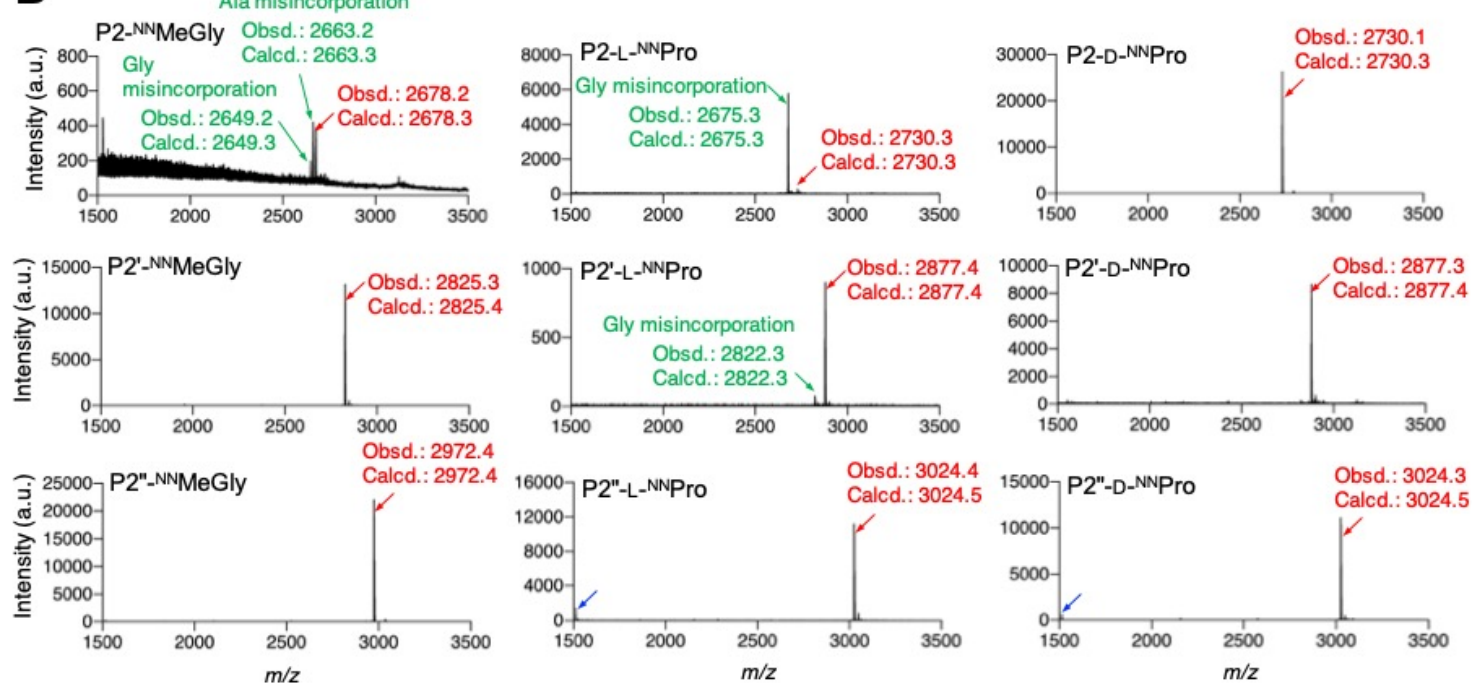

Supplementary Figure S3. MALDI-TOF MS of ribosomally synthesized model peptides containing multiple $\alpha$-aminoxy acids or $\alpha$-hydrazino acids. (A) Peptide P2 containing $\alpha$-aminoxy acids. (B) Peptides P2, P2', and P2" containing $\alpha$-hydrazino acids. (C) Peptides P1 and P2 containing D-Pro. (D, E) Peptides P3, P4, and P5 containing L- ${ }^{\mathrm{NO}} \mathrm{Ala}(\mathrm{D})$ or $\mathrm{D}^{\mathrm{NO}} \mathrm{Ala}(\mathrm{E})$. (F) Peptides P1 and P2 containing ${ }^{\mathrm{NO}}$ Gly or D- ${ }^{\mathrm{NN}}$ Pro incorporated by tRNA ${ }^{\mathrm{AsnE} 2}{ }_{\mathrm{CGG}}$. Translation was conducted in the presence of EF-P. The red and blue arrows indicate monovalent $\left([\mathrm{M}+\mathrm{H}]^{+}\right)$and divalent ions $\left([\mathrm{M}+2 \mathrm{H}]^{2+}\right)$ of desired products, respectively. The green arrows indicate byproducts derived from misincorporation at the CCG codon. The purple arrows indicate codon skipping byproducts that lack one ${ }^{\mathrm{NO}} \mathrm{Gly}$ or D- ${ }^{\mathrm{NN}}$ Pro residue. Asterisks denote template-independent impurities derived from the translation system. "Obsd." and "Calcd." indicate observed and calculated $\mathrm{m} / \mathrm{z}$ values, respectively. 

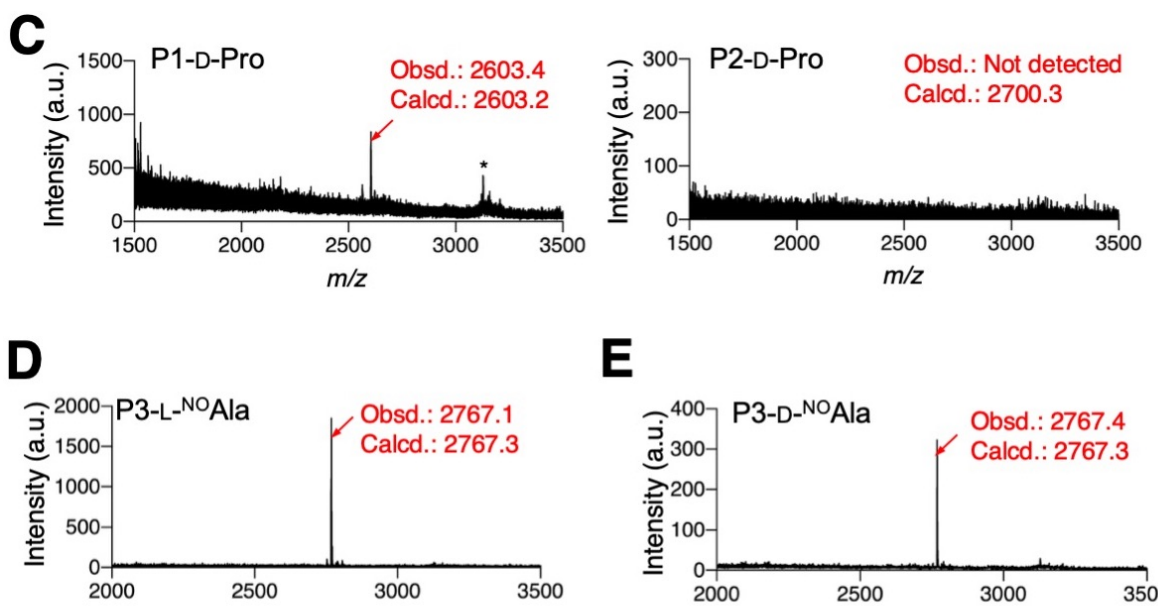

E
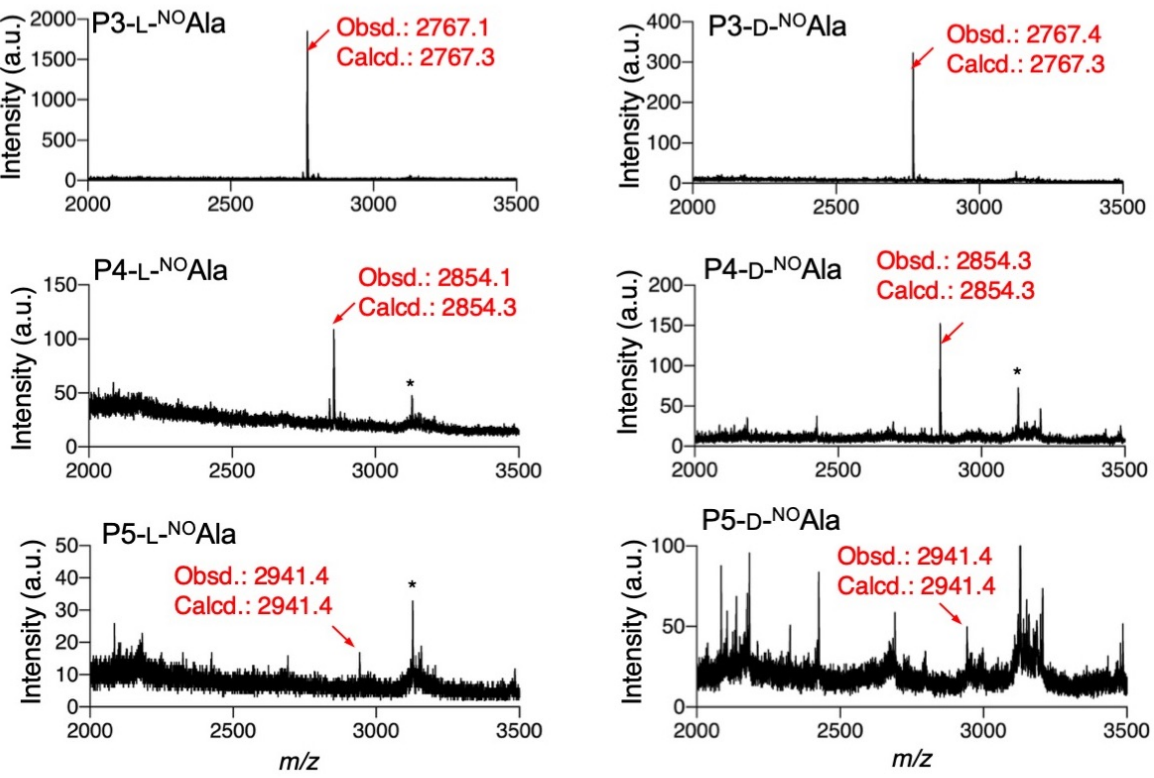

$\mathbf{F}$
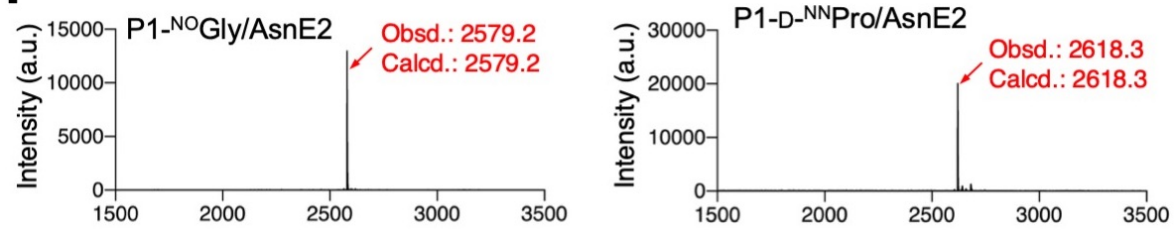

P2-NoGly/AsnE2

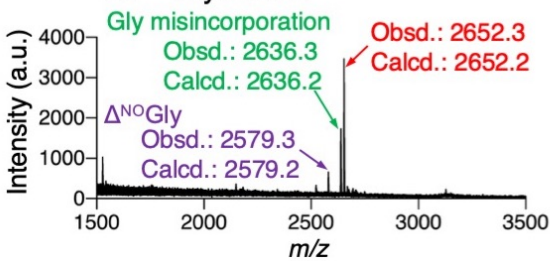

P2-D-NNPro/AsnE2

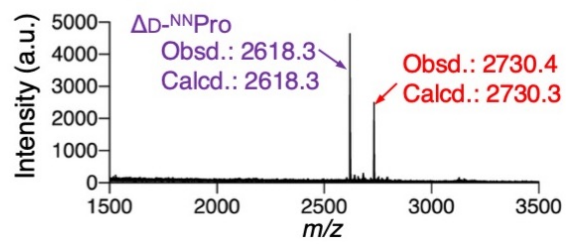

\section{Supplementary Figure S3 continued.}


A
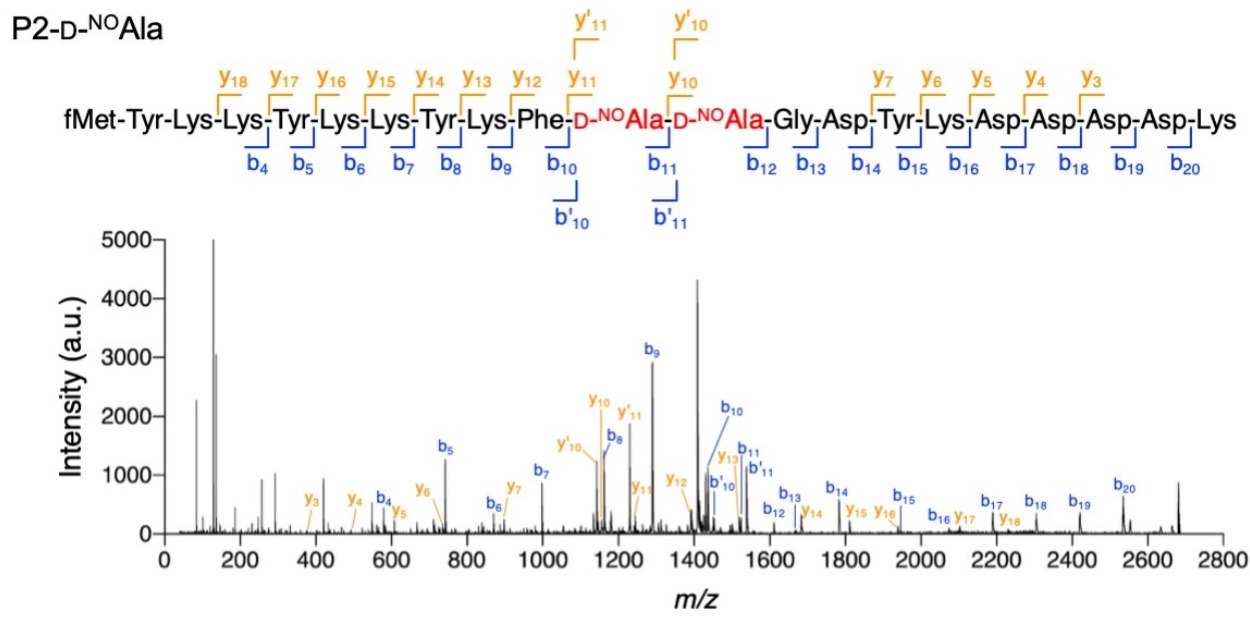

B
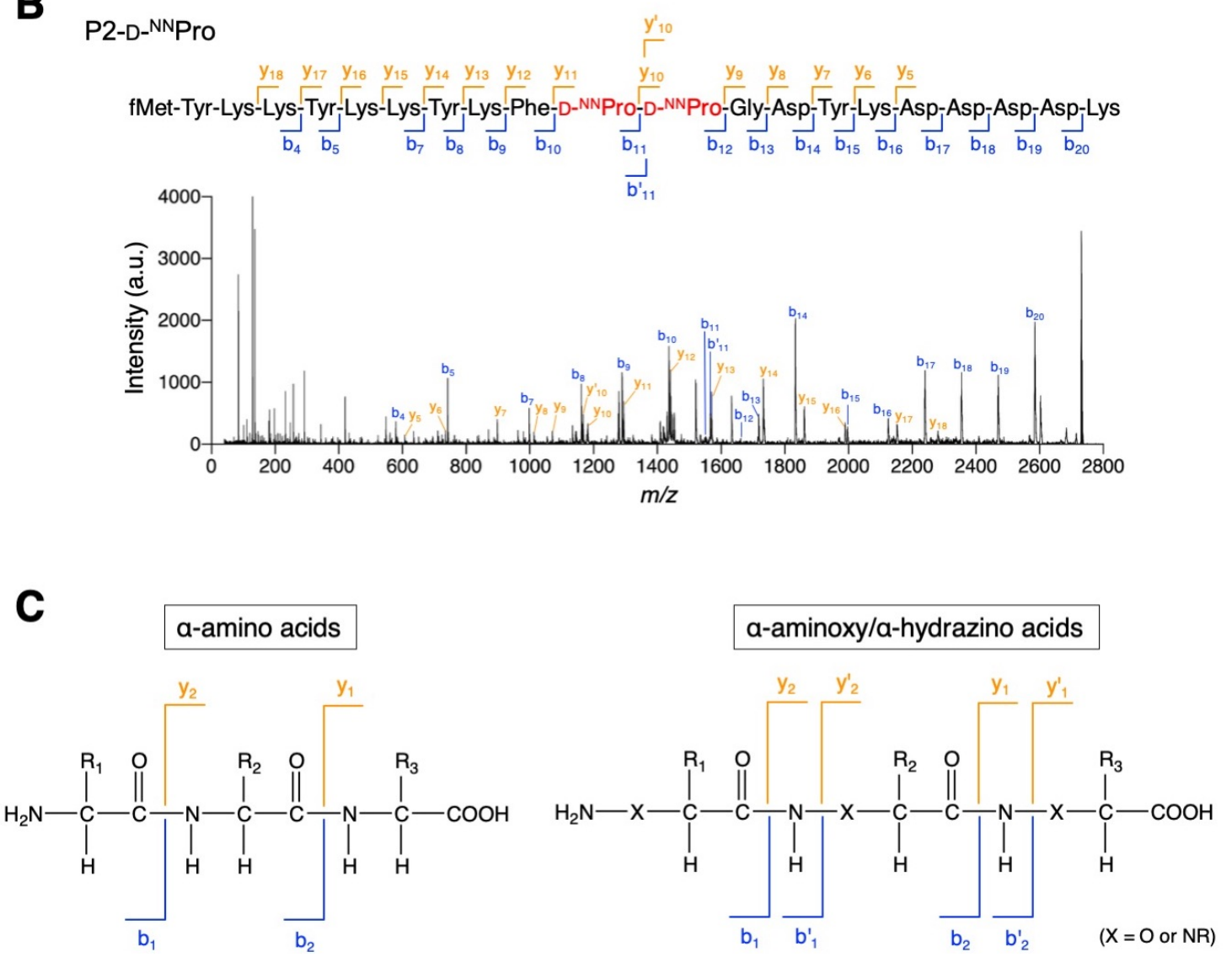

Supplementary Figure S4. De novo sequencing of translated peptides by MALDI-TOF/TOF MS/MS. (A, B) Fragmentation of P2-D- ${ }^{\mathrm{NO}} \mathrm{Ala}(\mathrm{A})$ and P2-D- ${ }^{\mathrm{NN}}$ Pro (B). The observed $\mathrm{b}$ and $\mathrm{b}^{\prime}$ ions are indicated in blue, and $\mathrm{y}$ and $\mathrm{y}^{\prime}$ ions are indicated in orange. The incorporation of $\mathrm{D}^{\mathrm{NO}}{ }^{\mathrm{N}} \mathrm{Ala}$ and $\mathrm{D}^{\mathrm{NN}} \mathrm{Pro}$ at targeted positions of $\mathrm{P} 2$ was confirmed. (C) Fragmentation sites of peptides consisting of $\alpha$-amino acids or $\alpha$-aminoxy/ $\alpha$-hydrazino acids. Fragmentation between $\mathrm{N}$ and $\mathrm{X}\left(\mathrm{X}=\mathrm{O}\right.$ or NR) yields $\mathrm{b}^{\prime}$ and $\mathrm{y}^{\prime}$ ions from $\alpha$-aminoxy $/ \alpha$-hydrazino acids. 

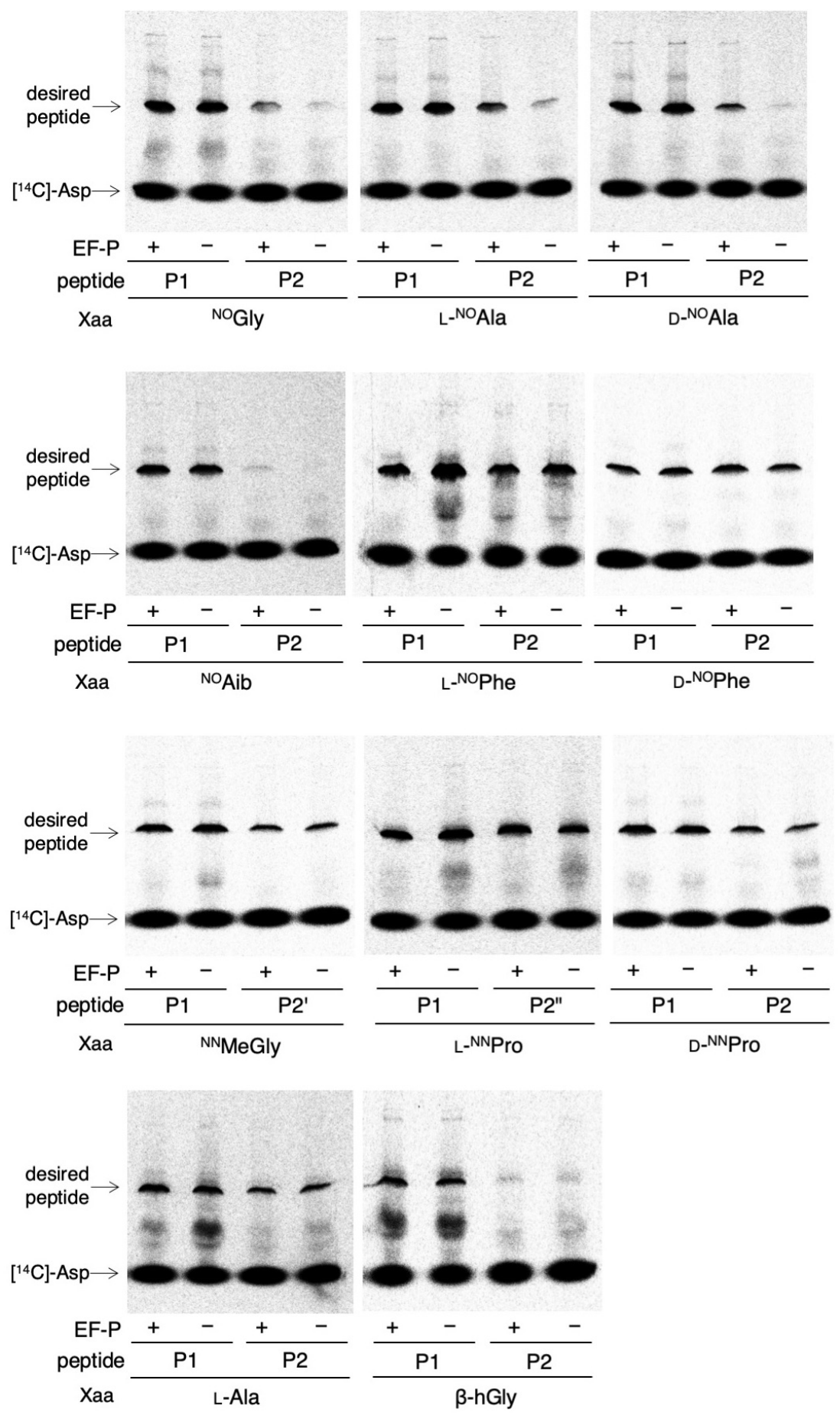

Supplementary Figure S5. Tricine SDS-PAGE analysis of translated peptides P1, P2, P2', and P2" containing $\alpha$-aminoxy or $\alpha$-hydrazino acids. See Figure 3D for quantification of bands. 
A mRNA (mR11): AUG UAC AAG AAG UAC AAAAAG UAC GCU GGU CCG ACU GCU flag UAA peptide (P11): fMet Tyr Lys Lys Tyr Lys Lys Tyr Ala Gly $\mathrm{Xaa}_{1} \mathrm{Xaa}_{2}$ Ala flag (stop) mRNA (mR11'): AUG UAC AAG AAG UAC AAA AAG UAC GCU GGU ACU CCG GCU flag UAA peptide (P11'): fMet Tyr Lys Lys Tyr Lys Lys Tyr Ala Gly $\mathbf{X a a}_{1} \mathbf{X a a}_{2}$ Ala flag (stop)

B

$\left(\mathrm{Xaa}_{1}, \mathrm{Xaa}_{2}\right.$ : arbitrary $\alpha$-aminoxy or $\alpha$-hydrazino acid)
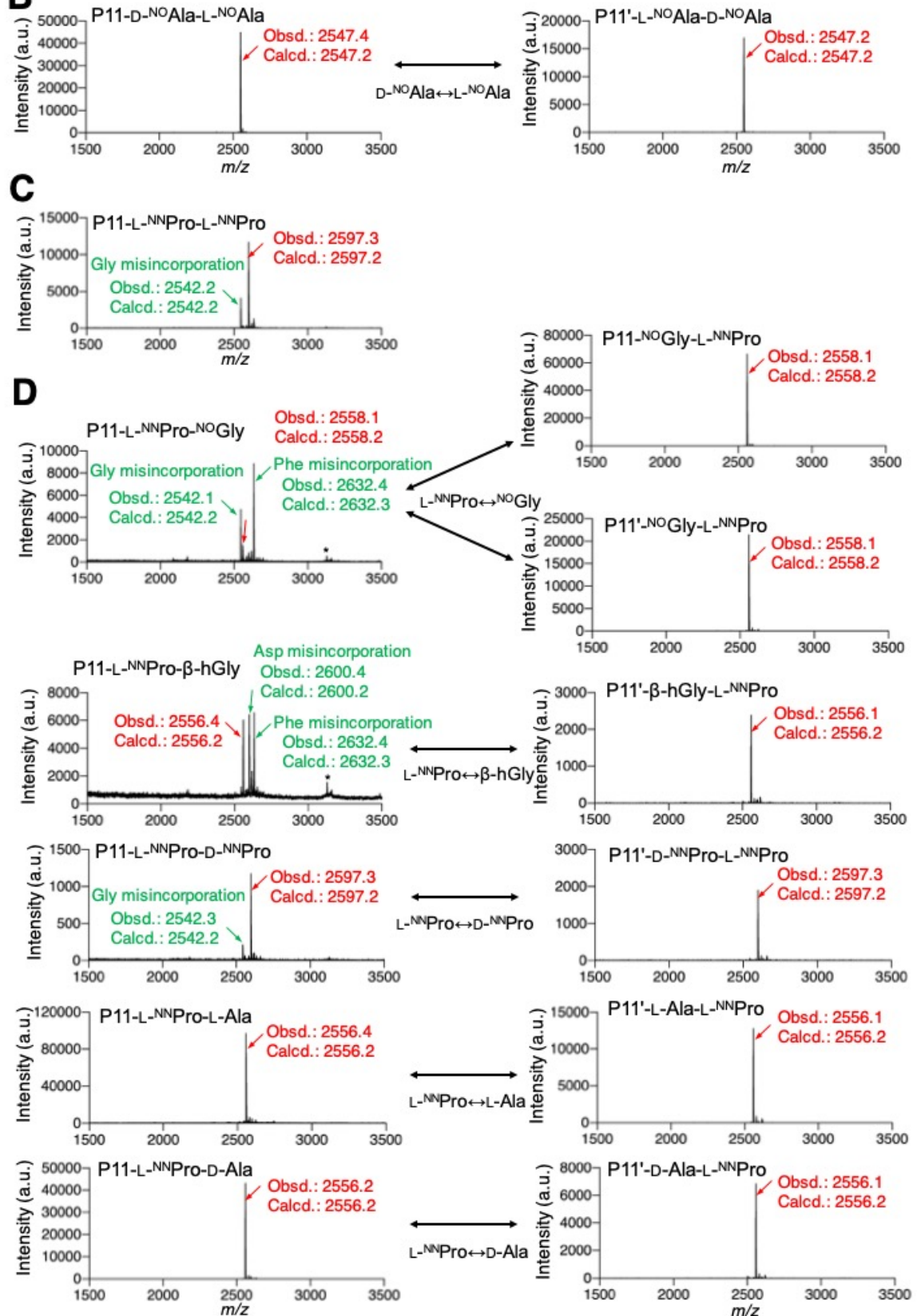

Supplementary Figure S6. Combinations of different $\alpha$-aminoxy and $\alpha$-hydrazino acids in consecutive elongation. (A) Sequences of mRNAs ( $\mathrm{mR} 11$ and $\left.\mathrm{mR} 11^{\prime}\right)$ and corresponding peptides (P11 and P11'). (B, C, D) MALDI-TOF MS of ribosomally synthesized P11-Xaa $1-\mathrm{Xaa}_{2}$ and $\mathrm{P} 11^{\prime}-\mathrm{Xaa}_{1}-\mathrm{Xaa}_{2}$ with combinations of $\alpha$-aminoxy acids, $\alpha$-hydrazino acids, and other amino acids as $\mathrm{Xaa}_{1}$ and $\mathrm{Xaa}_{2}$. Translation reactions were carried out in the presence of EF-P. Red arrows indicate monovalent ions $\left([\mathrm{M}+\mathrm{H}]^{+}\right)$of desired products. Green arrows indicate byproducts derived from misincorporation. "Obsd." and "Calcd." indicate observed and calculated $\mathrm{m} / \mathrm{z}$ values, respectively. Asterisks denote template-independent impurities derived from the translation system. 
A ${ }^{N O G l y-D B E},{ }^{1} \mathrm{H}$

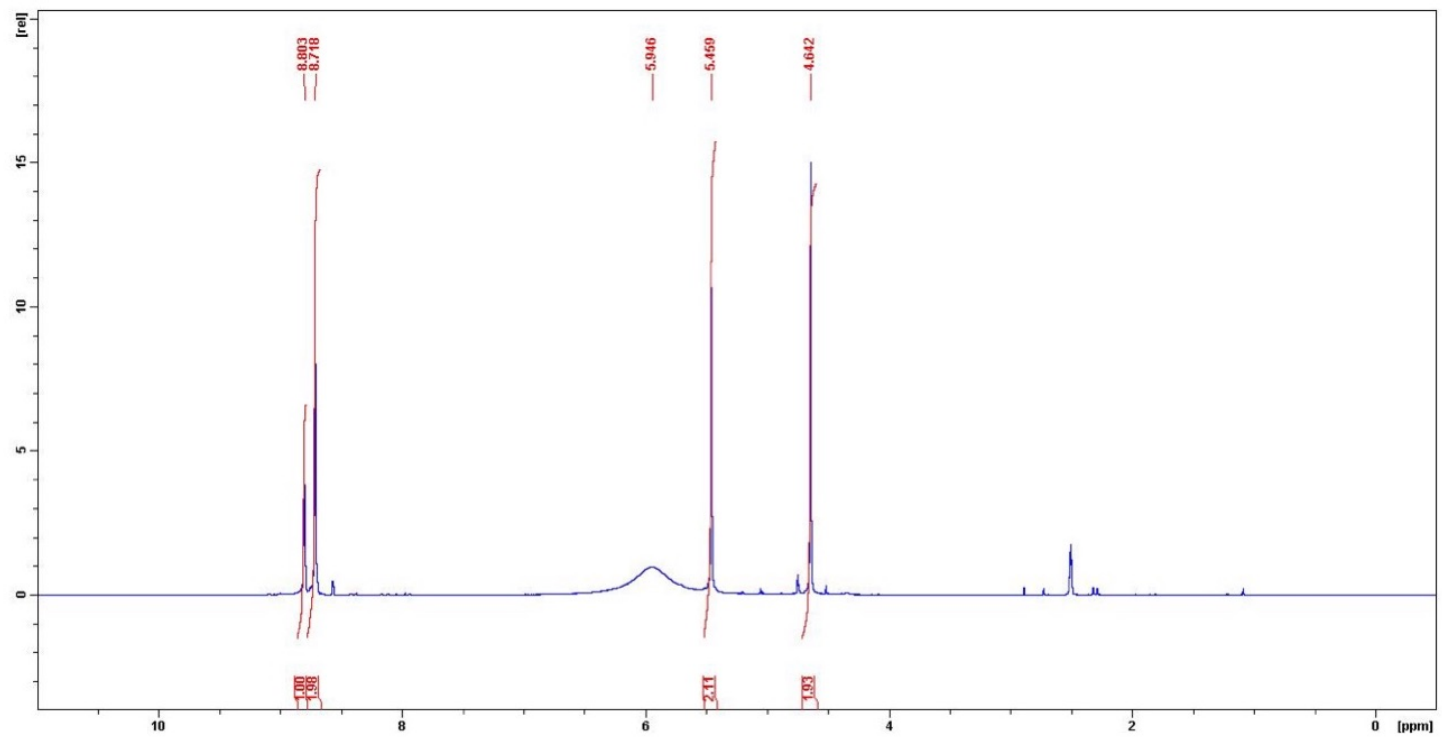

${ }^{1} \mathrm{H}$ NMR (300 MHz, DMSO-d 6 ): $\delta 8.803(\mathrm{~s}, 1 \mathrm{H}), 8.718(\mathrm{~s}, 2 \mathrm{H}), 5.459(\mathrm{~s}, 2 \mathrm{H}), 4.642(\mathrm{~s}, 2 \mathrm{H})$

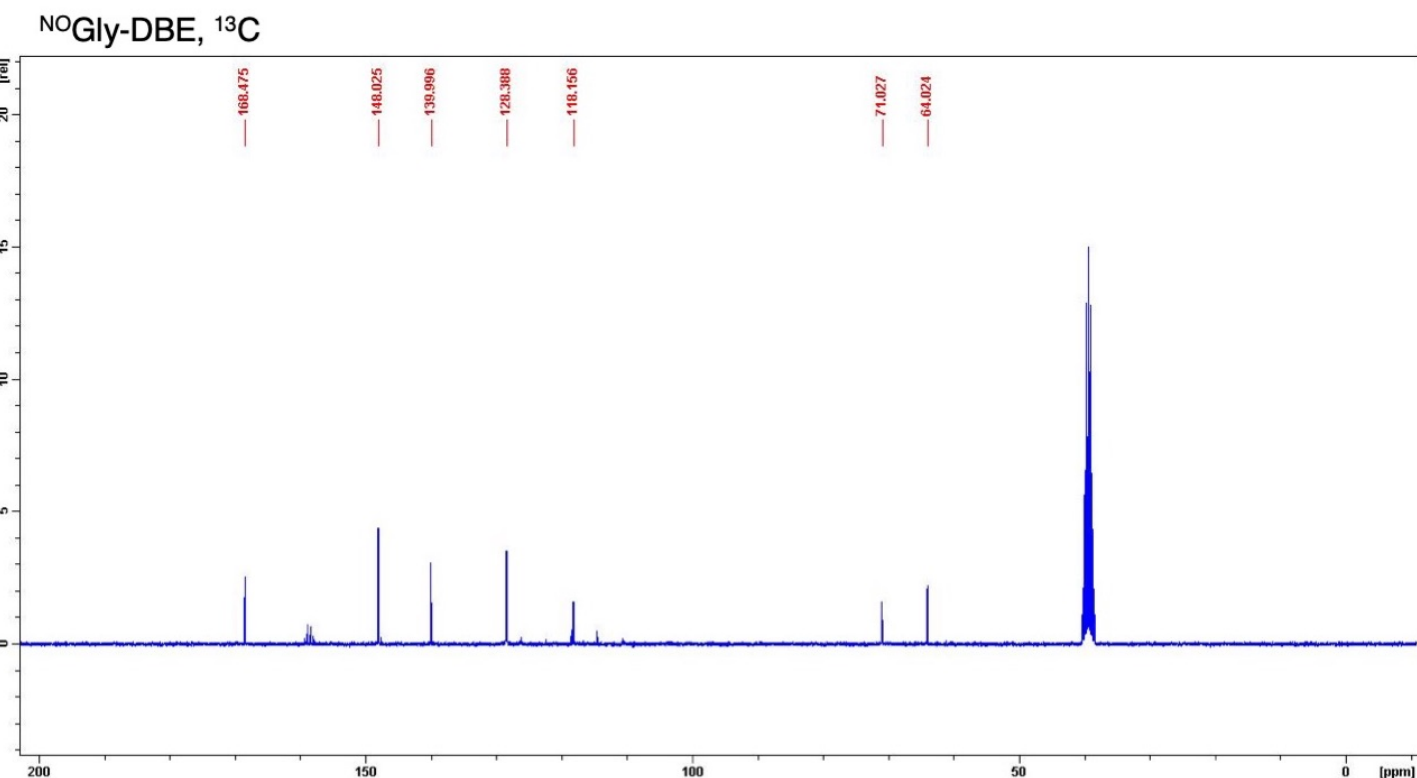

${ }^{13} \mathrm{C}$ NMR (300 MHz, DMSO-d ${ }_{6}$ ): $\delta 168.475,148.025,139.996,128.388,118.156,71.027,64.024$

Supplementary Figure S7. ${ }^{1} \mathrm{H}$ and ${ }^{13} \mathrm{C}$ NMR spectra of esterified $\alpha$-aminoxy and $\alpha$-hydrazino acids. (A) ${ }^{\mathrm{NO}}$ Gly-DBE, (B) L- ${ }^{\mathrm{NO}}$ Ala-DBE, (C) D- ${ }^{\mathrm{NO}}$ Ala-DBE, (D) ${ }^{\mathrm{NO}}$ Aib-DBE, (E) L- ${ }^{\mathrm{NO}} \mathrm{Phe}-\mathrm{CME},(\mathrm{F})$ D- ${ }^{\mathrm{NO}}$ Phe-CME, $(\mathrm{G}){ }^{\mathrm{NN}}$ MeGly-DBE, (H) L- ${ }^{\mathrm{NN}}$ Pro-DBE, and (I) D- ${ }^{\mathrm{NN}}$ Pro-DBE. 
B L-NOAla-DBE, ${ }^{1} \mathrm{H}$

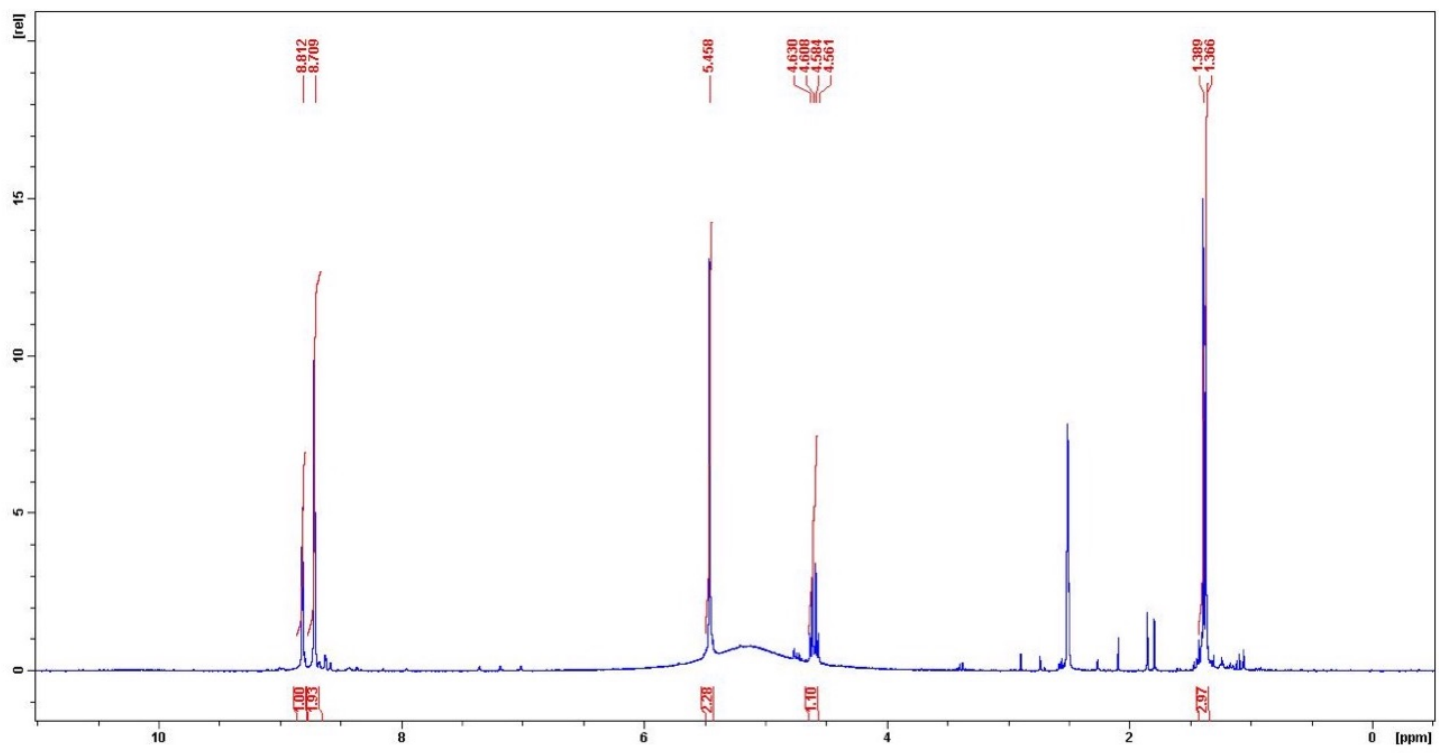

${ }^{1} \mathrm{H}$ NMR (300 MHz, DMSO-d $\left.{ }_{6}\right): \delta 8.812(\mathrm{~s}, 1 \mathrm{H}), 8.709(\mathrm{~s}, 2 \mathrm{H}), 5.458(\mathrm{~s}, 2 \mathrm{H}), 4.630-4.561(\mathrm{q}, J=6.6,7.2$, and $6.9 \mathrm{~Hz}, 1 \mathrm{H})$, $1.389-1.366(\mathrm{~d}, J=6.9 \mathrm{~Hz}, 3 \mathrm{H})$

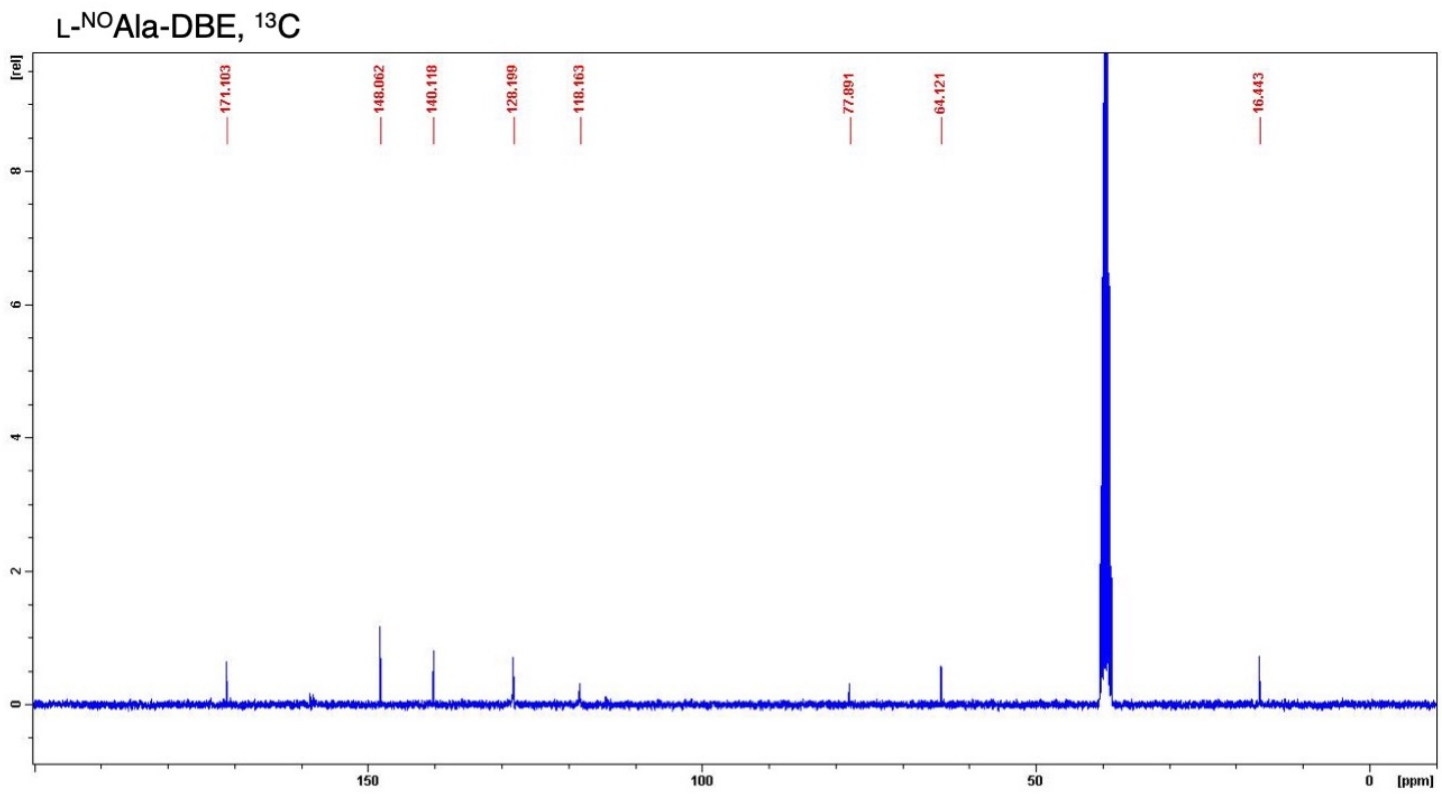

${ }^{13} \mathrm{C}$ NMR (300 MHz, DMSO-d ${ }_{6}$ ): $\delta$ 171.103, 148.062, 140.118, 128.199, 118.163, 77.891, 64.121, 16.443

Supplementary Figure S7 continued. 
C ${ }^{D-N O A l a-D B E,}{ }^{1 H}$

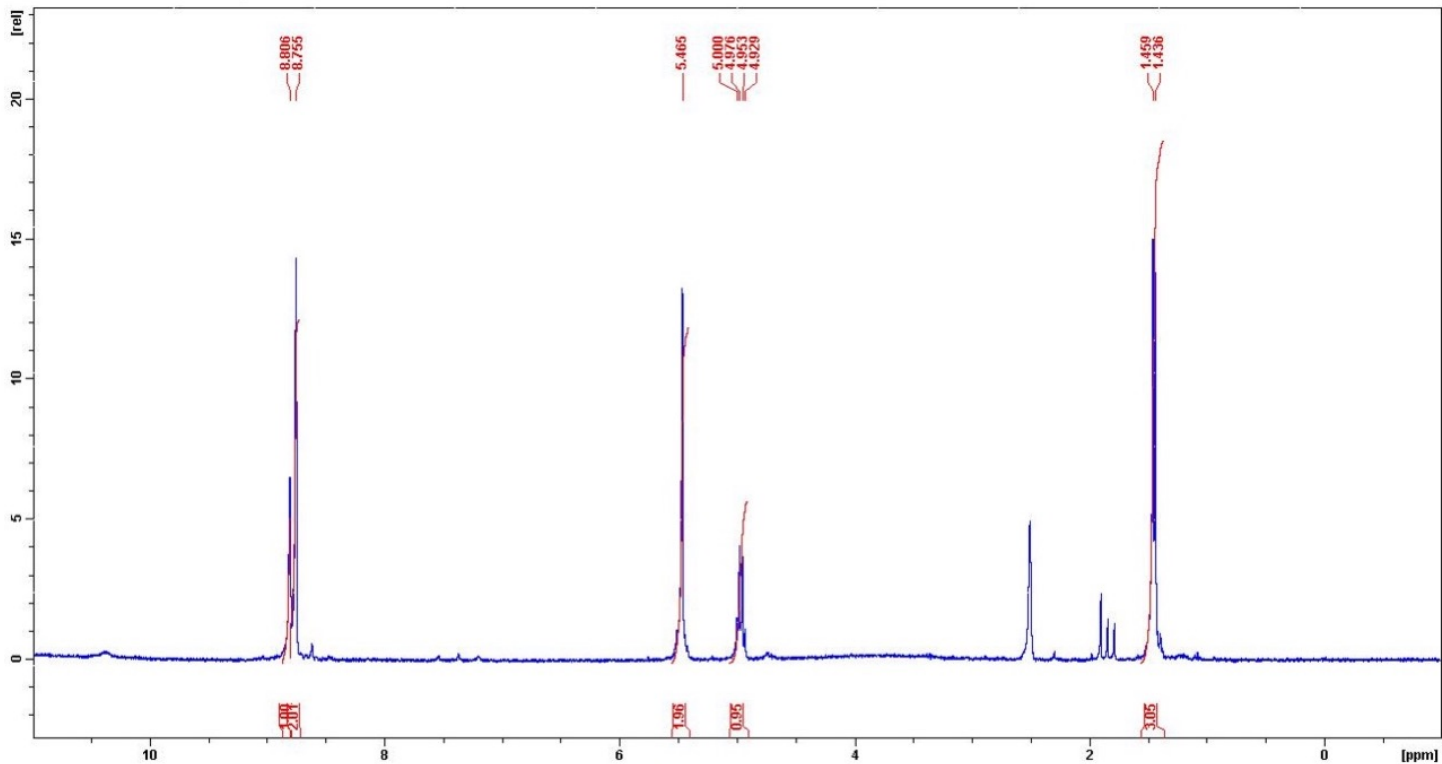

${ }^{1} \mathrm{H}$ NMR (300 MHz, DMSO-d $\left.{ }_{6}\right): \delta 8.806(\mathrm{~s}, 1 \mathrm{H}), 8.755(\mathrm{~s}, 2 \mathrm{H}), 5.465(\mathrm{~s}, 2 \mathrm{H}), 5.000-4.929(\mathrm{q}, J=7.2,6.9$, and 7.2 Hz, 1H), $1.459-1.436(\mathrm{~d}, J=6.9 \mathrm{~Hz}, 3 \mathrm{H})$

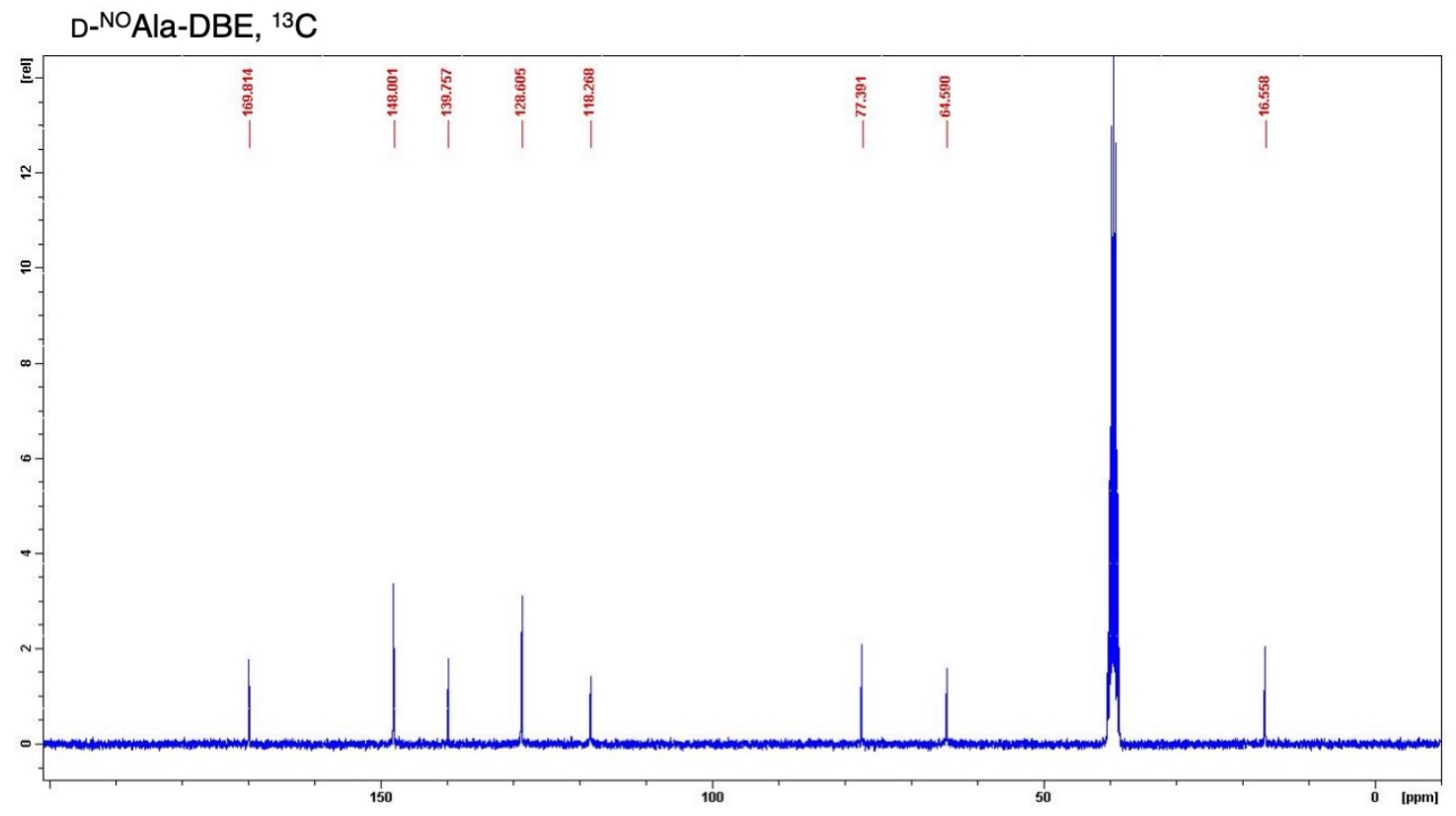

${ }^{13}$ C NMR (300 MHz, DMSO-d ${ }_{6}$ ): $\delta$ 169.814, 148.001, 139.757, 128.605, 118.268, 77.391, 64.590, 16.558

\section{Supplementary Figure S7 continued.}




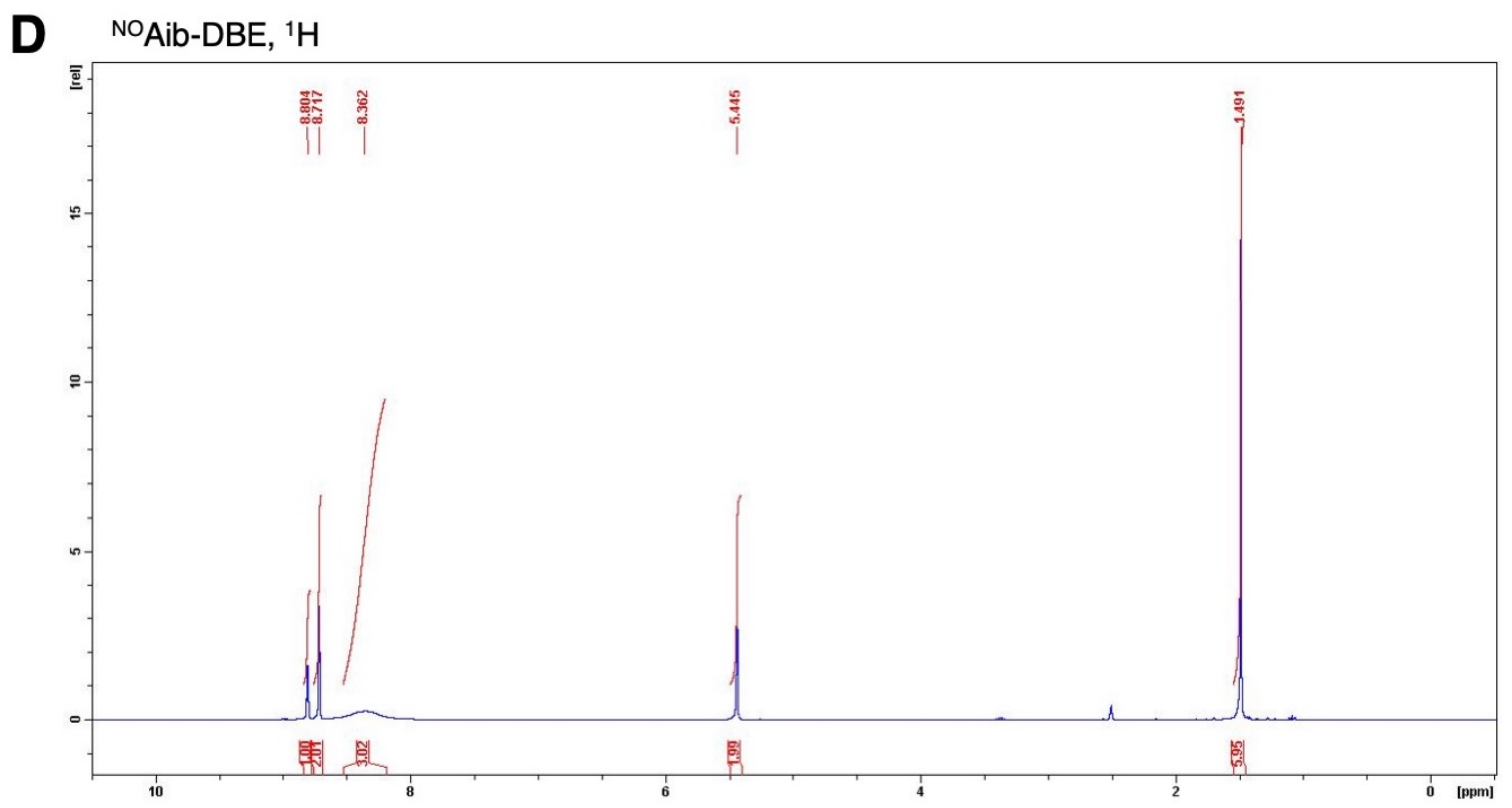

${ }^{1} \mathrm{H}$ NMR (300 MHz, DMSO-d 6 ): $\delta 8.804$ (s, 1H), 8.717 (s, 2H), 5.445 (s, 2H), 1.491 (s, 6H)

${ }^{\text {NOAib-DBE, }}{ }^{13} \mathrm{C}$

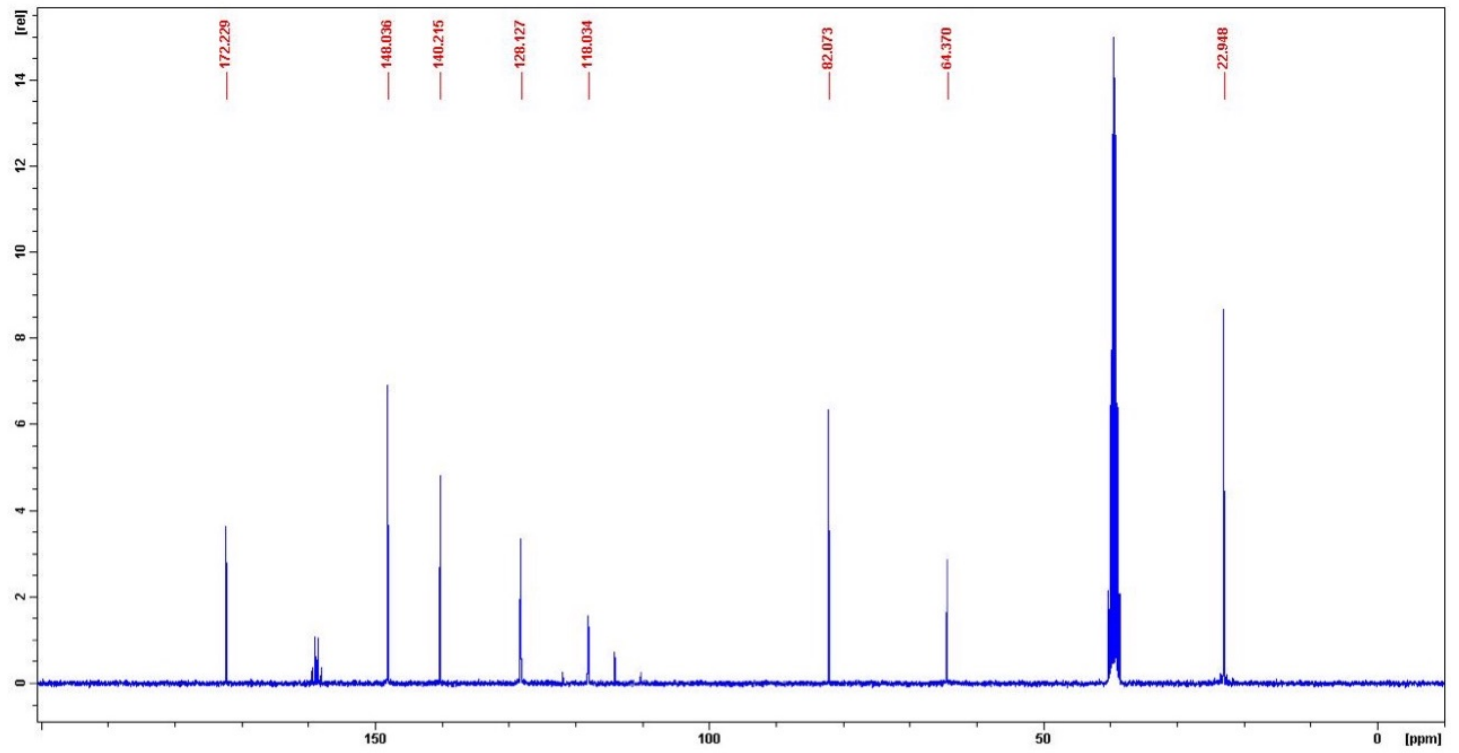

${ }^{13}$ C NMR (300 MHz, DMSO-d $\left.{ }_{6}\right): \delta 172.229,148.036,140.215,128.127,118.034,82.073,64.370,22.948$

Supplementary Figure S7 continued. 


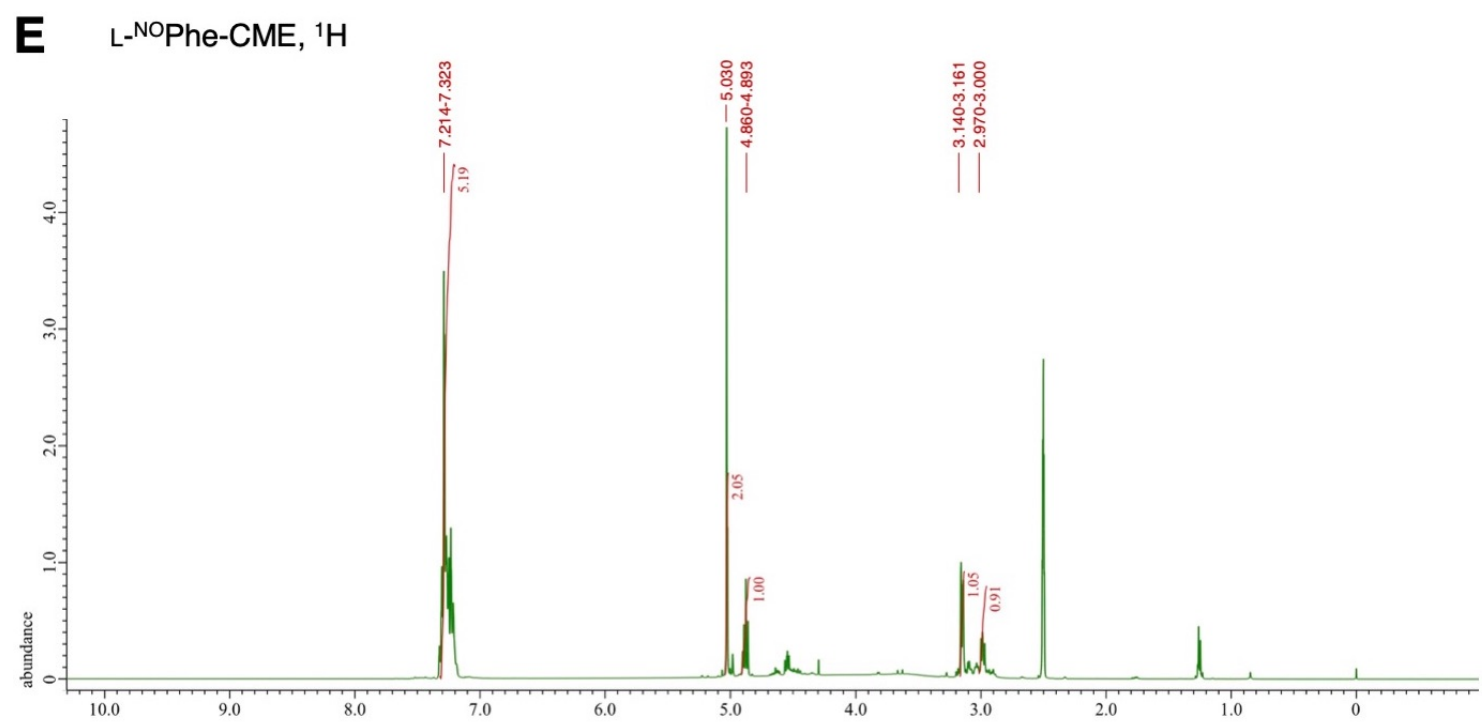

${ }^{1} \mathrm{H}$ NMR (400 MHz, DMSO-d 6 ): $\delta 7.214-7.323(\mathrm{~m}, 5 \mathrm{H}), 5.030$ (s, 2H), 4.860-4.893 (t, $\left.J=6.6,6.6 \mathrm{~Hz}, 1 \mathrm{H}\right), 3.140-3.161(\mathrm{~m}, 1 \mathrm{H})$, $2.970-3.000(\mathrm{~m}, 1 \mathrm{H})$

L-NOPhe-DBE, ${ }^{13} \mathrm{C}$

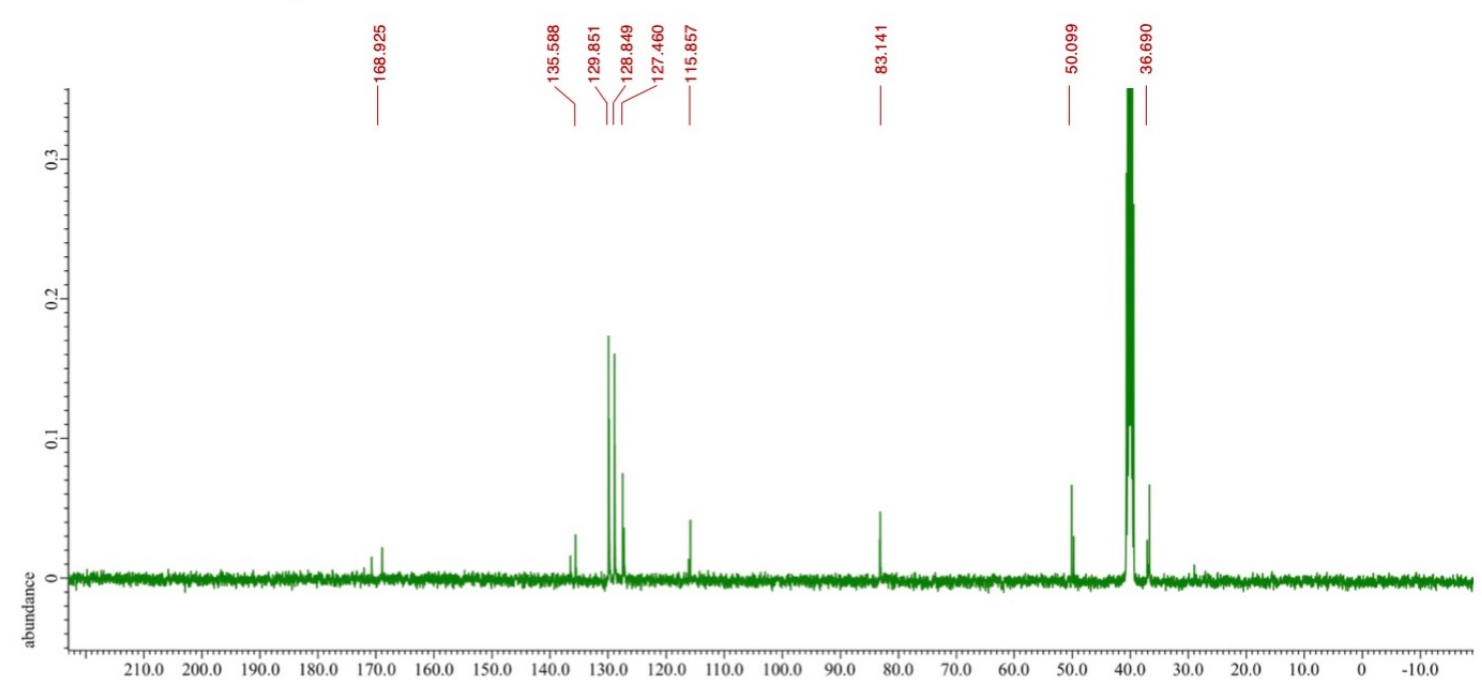

${ }^{13} \mathrm{C}$ NMR (400 MHz, DMSO-d ${ }_{6}$ ): $\delta$ 168.925, 135.588, 129.901, 129.801, 128.878, 128.820, 127.460, 115.857, 83.141, 50.099, 36.690

\section{Supplementary Figure S7 continued.}




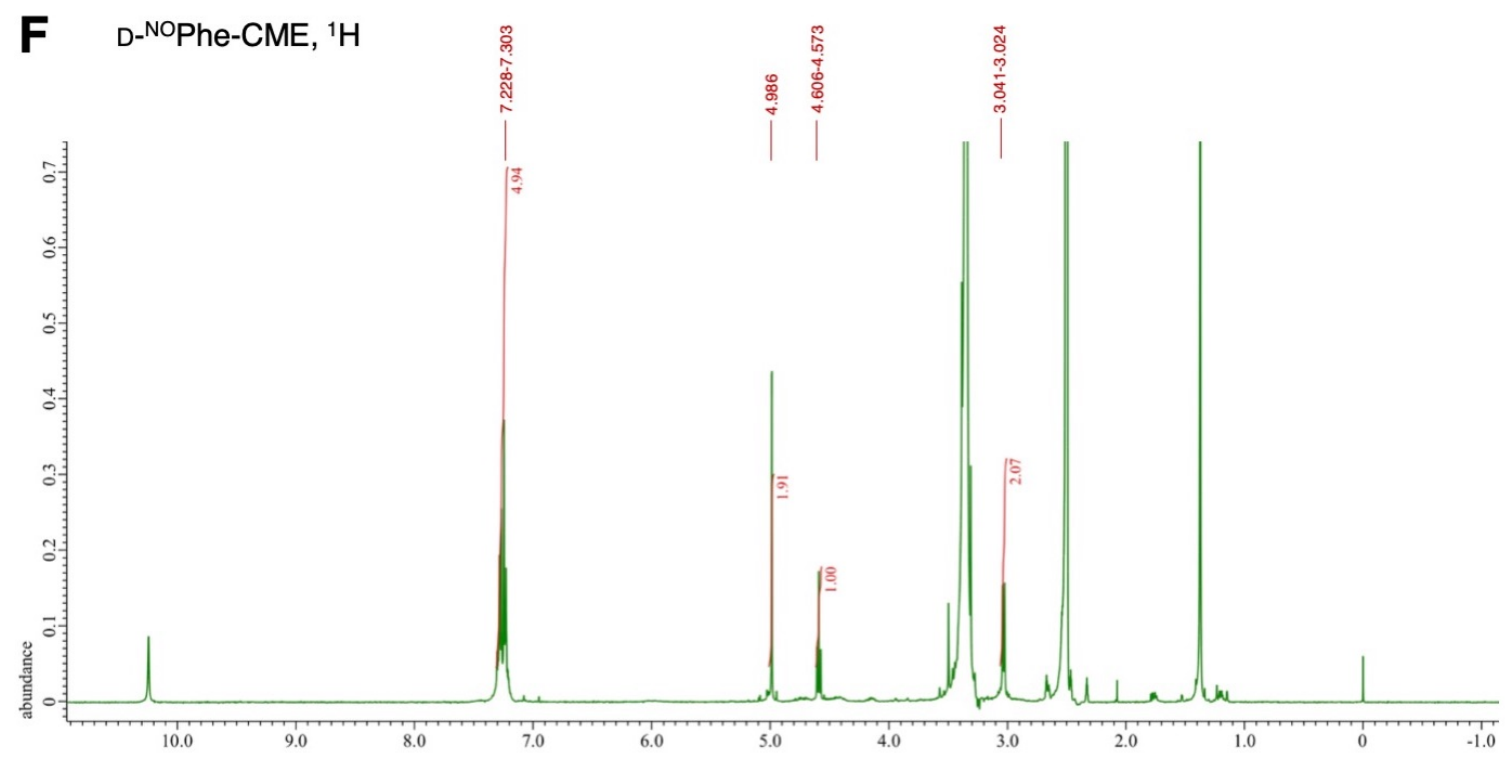

${ }^{1} \mathrm{H}$ NMR (400 MHz, DMSO-d 6 ): $\delta$ 7.288-7.303 (m, 5H), 4.986 (s, 2H), 4.606-4.573 (t, $\left.J=6.4,6.8 \mathrm{~Hz}, 1 \mathrm{H}\right), 3.041-3.024$ (m, $\left.2 \mathrm{H}\right)$

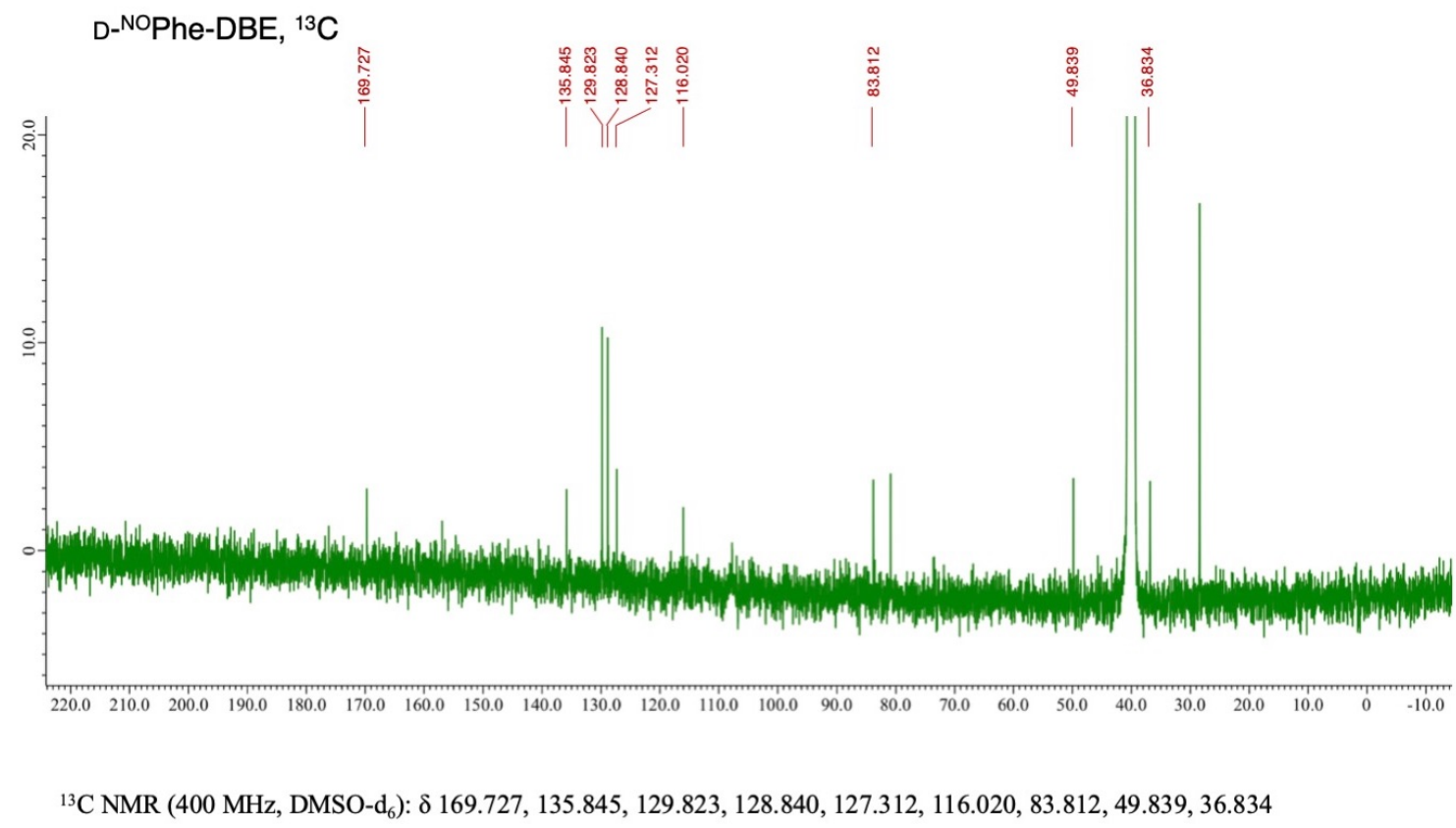

Supplementary Figure S7 continued. 
G $\quad{ }^{N N M e G l y-D B E},{ }^{1} \mathrm{H}$

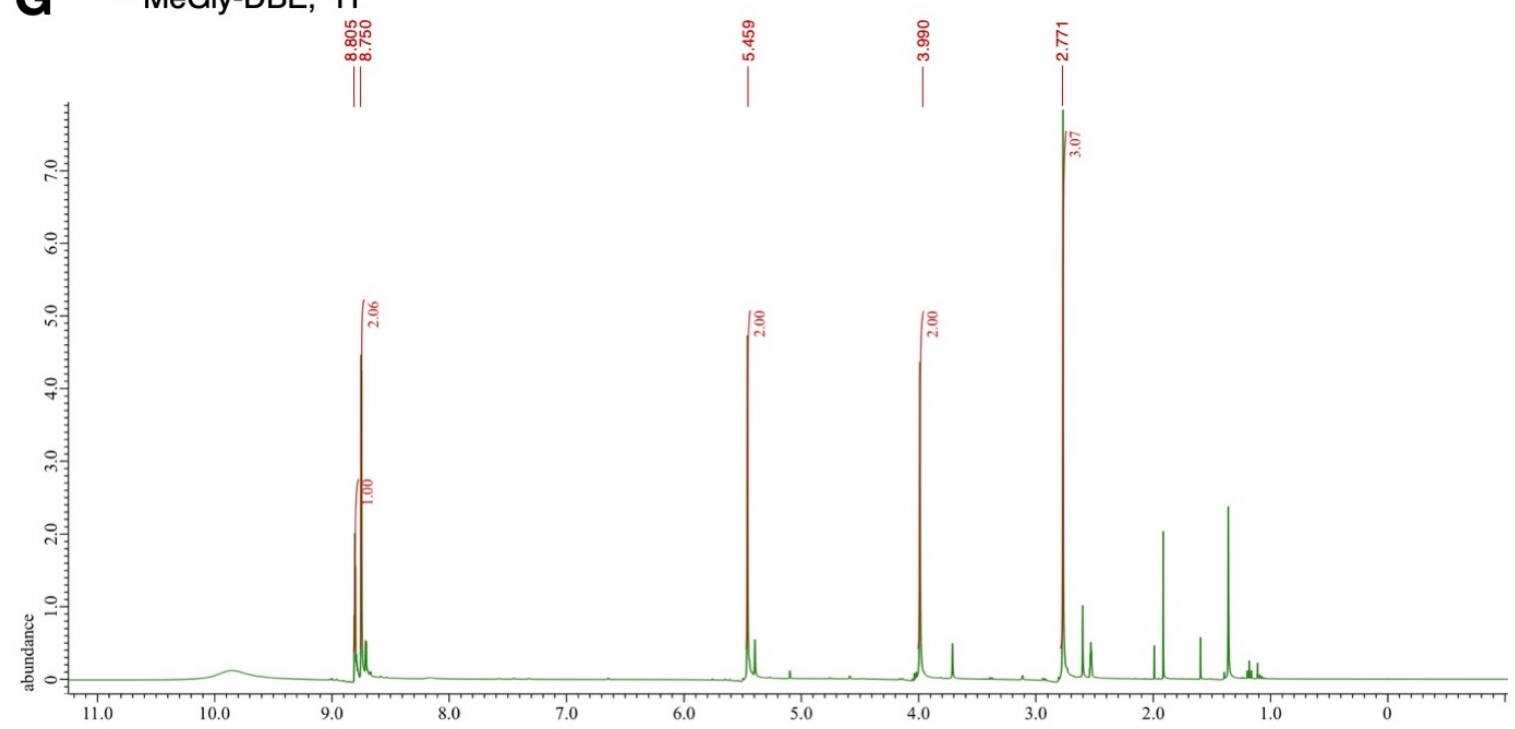

${ }^{1} \mathrm{H}$ NMR (400 MHz, DMSO-d $\left.{ }_{6}\right): \delta 8.805(\mathrm{~s}, 1 \mathrm{H}), 8.750(\mathrm{~s}, 2 \mathrm{H}), 5.459(\mathrm{~s}, 2 \mathrm{H}), 3.990(\mathrm{~s}, 2 \mathrm{H}), 2.771(\mathrm{~s}, 3 \mathrm{H})$

${ }^{\mathrm{NN} M e G l y-D B E},{ }^{13} \mathrm{C}$

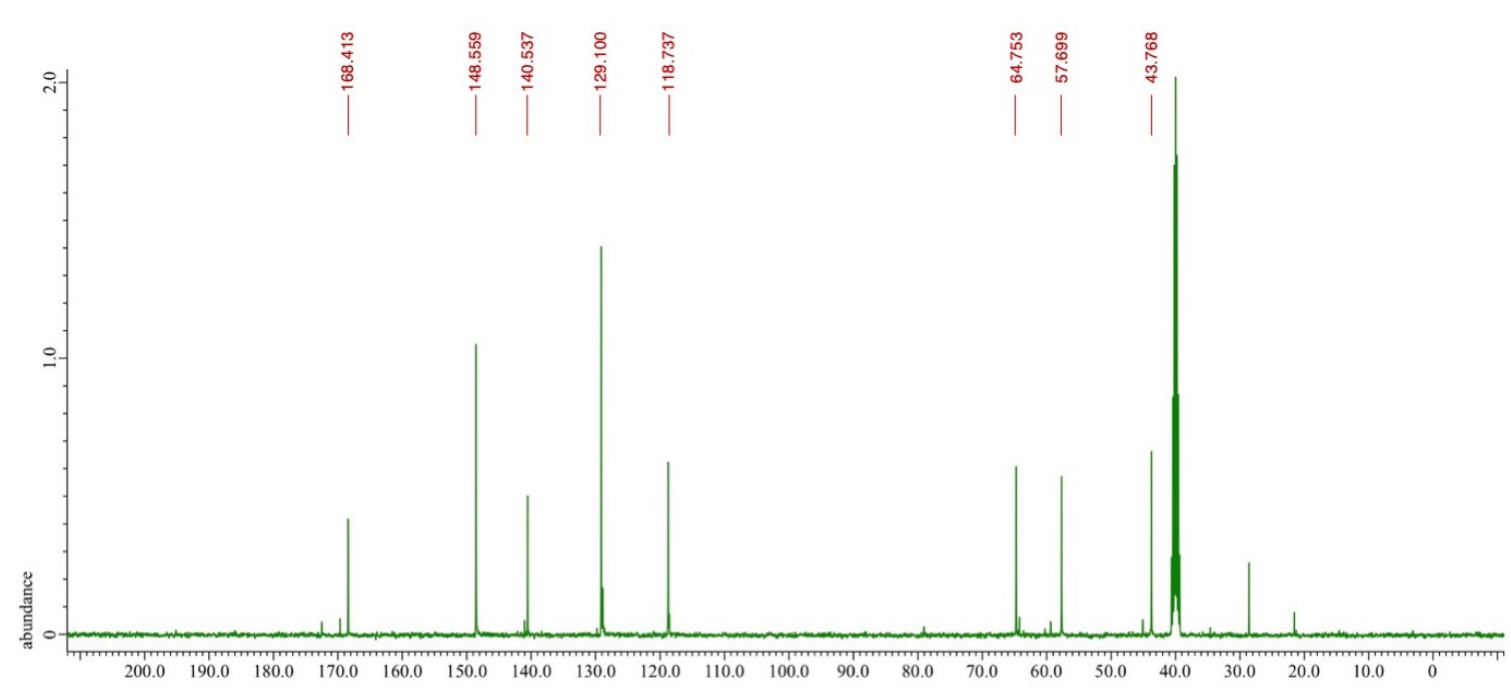

${ }^{13} \mathrm{C}$ NMR $\left(400 \mathrm{MHz}, \mathrm{DMSO}-\mathrm{d}_{6}\right): \delta 168.413,148.559,140.537,129.100,118.737,64.753,57.699,43.768$

\section{Supplementary Figure S7 continued.}




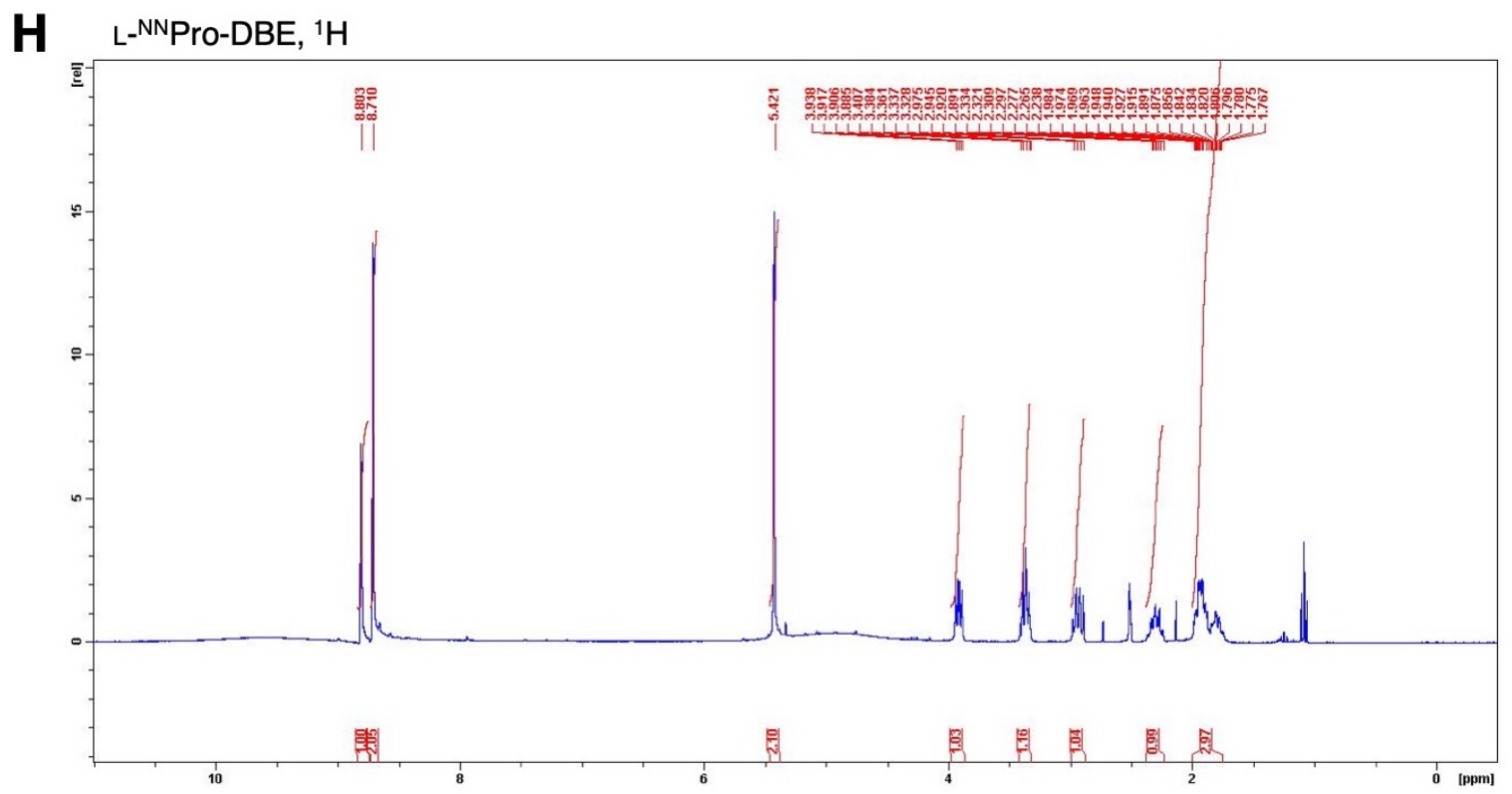

${ }^{1} \mathrm{H}$ NMR $\left(300 \mathrm{MHz}, \mathrm{DMSO}_{\mathrm{d}}\right.$ ): $\delta 8.803(\mathrm{~s}, 1 \mathrm{H}), 8.710(\mathrm{~s}, 2 \mathrm{H}), 5.421(\mathrm{~s}, 2 \mathrm{H}), 3.938-3.885(\mathrm{~m}, 1 \mathrm{H}), 3.407-3.328(\mathrm{~m}, 1 \mathrm{H})$, $2.975-2.891(\mathrm{~m}, 1 \mathrm{H}), 2.334-2.238(\mathrm{~m}, 1 \mathrm{H}), 1.984-1.767(\mathrm{~m}, 3 \mathrm{H})$

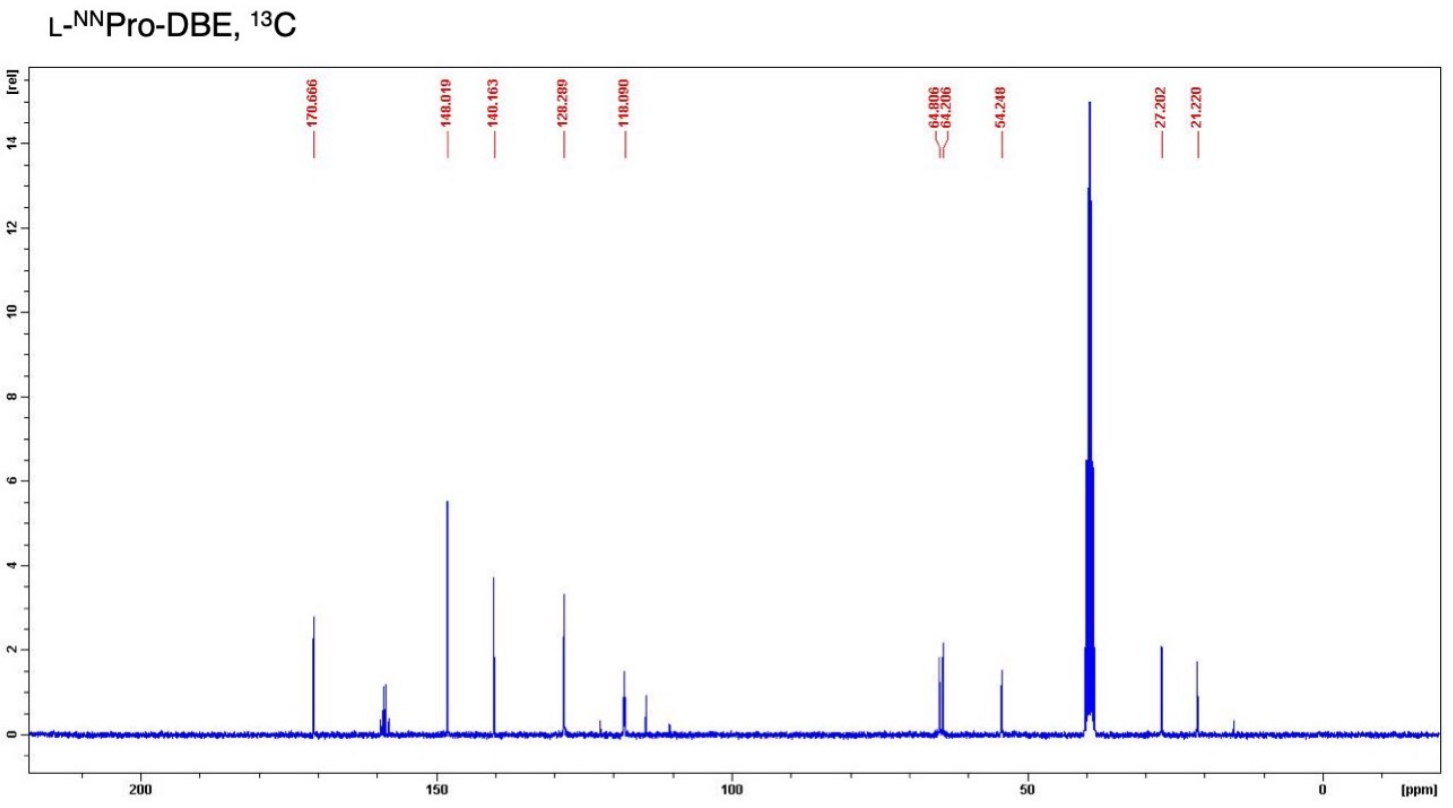

${ }^{13} \mathrm{C}$ NMR (300 MHz, DMSO-d $\left.{ }_{6}\right): \delta 170.666,148.019,140.163,128.289,118.090,64.806,64.206,54.248,27.202,21.220$

Supplementary Figure S7 continued. 


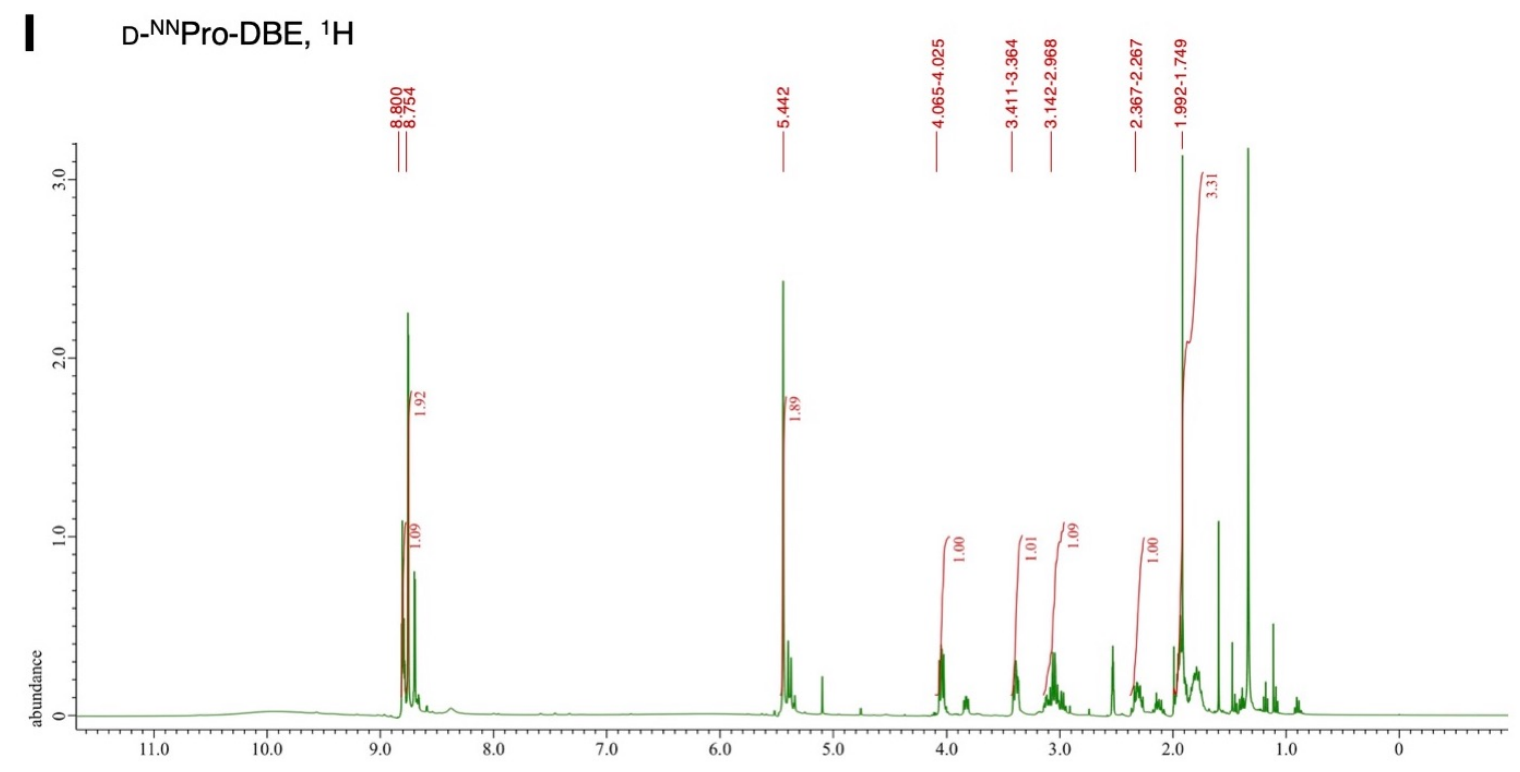

${ }^{1} \mathrm{H}$ NMR (400 MHz, DMSO-d $\mathrm{d}_{6}$ ): $\delta 8.800(\mathrm{~s}, 1 \mathrm{H}), 8.754(\mathrm{~s}, 2 \mathrm{H}), 5.442(\mathrm{~s}, 2 \mathrm{H}), 4.065-4.025(\mathrm{~m}, 1 \mathrm{H}), 3.411-3.364(\mathrm{~m}, 1 \mathrm{H})$, $3.142-2.968(\mathrm{~m}, 1 \mathrm{H}), 2.367-2.267(\mathrm{~m}, 1 \mathrm{H}), 1.992-1.749$ (m, 3H)

D-NNPro-DBE, ${ }^{13} \mathrm{C}$

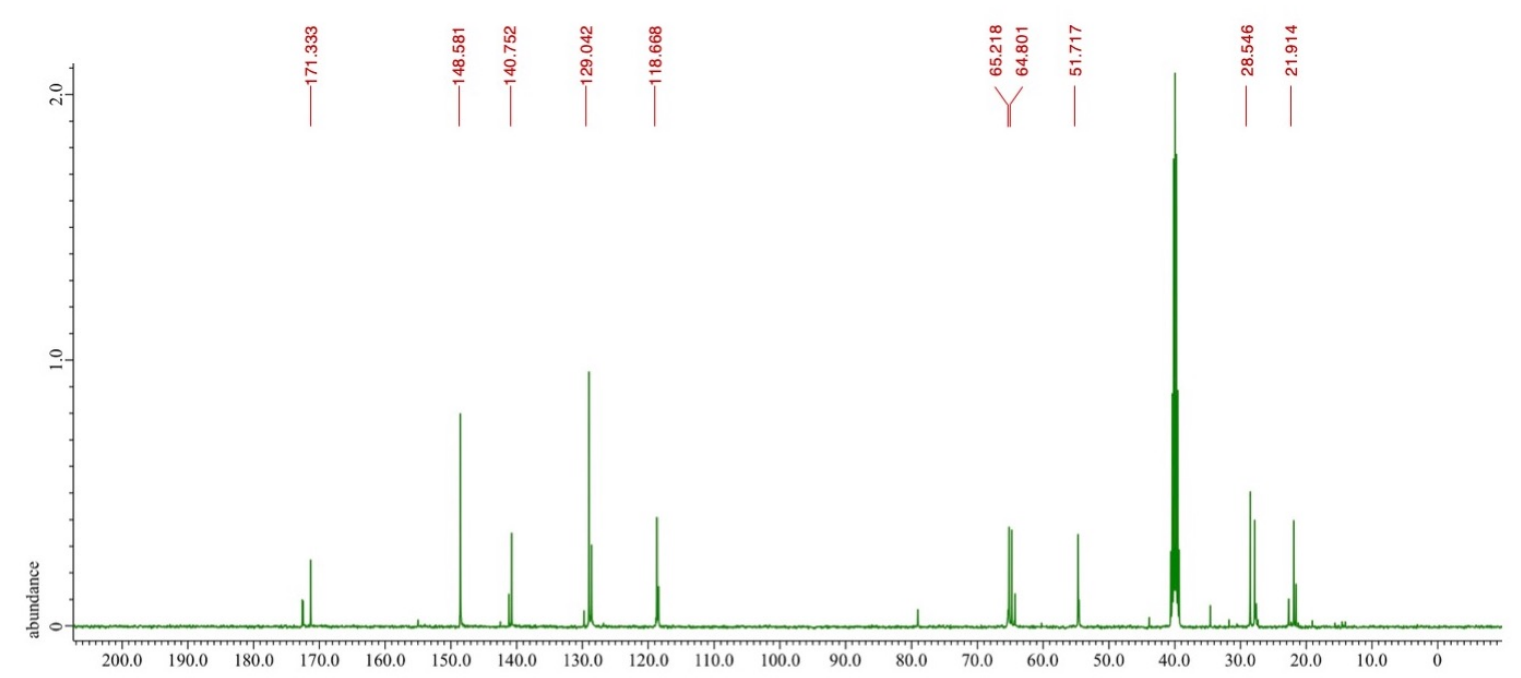

${ }^{13} \mathrm{C}$ NMR (400 MHz, DMSO-d ${ }_{6}$ ): $\delta 171.333,148.581,140.752,129.042,118.668,65.218,64.801,51.717,28.546,21.914$

\section{Supplementary Figure S7, continued.}


Supplementary Table S1. Conditions of acylation reactions. Flexizyme-catalyzed acylation reactions were conducted in $50 \mathrm{mM}$ HEPES-KOH (pH 7.5 or 8.0 ) or $50 \mathrm{mM}$ bicine-KOH (pH 8.5 or 9.0) with $600 \mathrm{mM} \mathrm{MgCl}_{2}, 20 \% \mathrm{DMSO}, 25 \mu \mathrm{M} \mathrm{dFx}$ or eFx, $25 \mu \mathrm{M} \mu \mathrm{hRNA}$ or tRNA, and 5 $\mathrm{mM}$ esterified substrate.

\begin{tabular}{|c|c|c|c|c|c|c|}
\hline Substrate & $\begin{array}{c}\text { Conc. of } \\
\text { substrate } \\
(\mathbf{m M})\end{array}$ & $\begin{array}{c}\text { Conc. of } \\
\text { flexizyme } \\
(\mu \mathrm{M})\end{array}$ & $\begin{array}{c}\text { Conc. of } \\
\boldsymbol{\mu h R N A ~ o r ~} \\
\text { tRNA }(\boldsymbol{\mu M})\end{array}$ & $\mathbf{p H}$ & $\begin{array}{c}\text { Temp. } \\
\left({ }^{\circ} \mathrm{C}\right)\end{array}$ & $\begin{array}{c}\text { Time } \\
\text { (h) }\end{array}$ \\
\hline${ }^{\mathrm{NO}}$ Gly-DBE $(+\mathrm{dFx})$ & 5 & 25 & 25 & 8.5 & 4 & 24 \\
\hline L- ${ }^{\mathrm{NO}}$ Ala-DBE $(+\mathrm{dFx})$ & 5 & 25 & 25 & 8.5 & 4 & 24 \\
\hline $\mathrm{D}-^{\mathrm{NO}}$ Ala-DBE $(+\mathrm{dFx})$ & 5 & 25 & 25 & 9.0 & 4 & 24 \\
\hline${ }^{\mathrm{NO}} \mathrm{Aib}-\mathrm{DBE}(+\mathrm{dFx})$ & 5 & 25 & 25 & 9.0 & 4 & 72 \\
\hline L- ${ }^{\mathrm{NO}} \mathrm{Phe}-\mathrm{CME}(+\mathrm{eFx})$ & 5 & 25 & 25 & 8.5 & 4 & 48 \\
\hline $\mathrm{D}^{\mathrm{NO}} \mathrm{Phe}-\mathrm{CME}(+\mathrm{eFx})$ & 5 & 25 & 25 & 9.0 & 4 & 48 \\
\hline${ }^{\mathrm{NN}}$ MeGly-DBE $(+\mathrm{dFx})$ & 5 & 25 & 25 & 8.0 & 4 & 24 \\
\hline $\mathrm{L}^{\mathrm{NN}}$ Pro-DBE $(+\mathrm{dFx})$ & 5 & 25 & 25 & 8.0 & 4 & 24 \\
\hline D- ${ }^{\mathrm{NN}}$ Pro-DBE $(+\mathrm{dFx})$ & 5 & 25 & 25 & 8.0 & 4 & 48 \\
\hline L-Ala-DBE (+dFx) & 5 & 25 & 25 & 7.5 & 4 & 2 \\
\hline D-Ala-DBE $(+d F x)$ & 5 & 25 & 25 & 7.5 & 4 & 2 \\
\hline D-Cys-DBE $(+\mathrm{dFx})$ & 5 & 25 & 25 & 7.5 & 4 & 6 \\
\hline D-Pro-DBE $(+d F x)$ & 5 & 25 & 25 & 7.5 & 4 & 2 \\
\hline$\beta$-hGly-DBE $(+\mathrm{dFx})$ & 5 & 25 & 25 & 9.0 & 4 & 22 \\
\hline${ }^{\mathrm{ClAc}} \mathrm{D}-\mathrm{Tyr}-\mathrm{CME}(+\mathrm{eFx})$ & 5 & 25 & 25 & 7.5 & 4 & 2 \\
\hline
\end{tabular}




\section{Materials and methods}

\section{Preparation of flexizymes and tRNAs}

Flexizymes ( $\mathrm{dFx}$ and $\mathrm{eFx})$ and tRNAs were prepared by in vitro transcription. Template DNAs were prepared by extension reactions using appropriate forward/reverse extension primer pairs, followed by PCR amplification using forward/reverse PCR primer pairs (see Supplementary Table S2 for the primer sequences). Then, transcription was carried out for $16 \mathrm{~h}$ at $37^{\circ} \mathrm{C}$ in $2-\mathrm{mL}$ reaction mixtures containing $40 \mathrm{mM}$ Tris- $\mathrm{HCl}(\mathrm{pH} 8.0), 22.5 \mathrm{mM} \mathrm{MgCl} 2,10 \mathrm{mM}$ DTT, $1 \mathrm{mM}$ spermidine, $0.01 \%$ Triton X-100, $5 \mathrm{mM}$ NTP mix, $0.04 \mathrm{U} / \mu \mathrm{L}$ RNasin RNase inhibitor (Promega), and $0.12 \mu \mathrm{M}$ T7 RNA polymerase. For tRNA transcription, the concentration of NTP mix was reduced to $3.75 \mathrm{mM}$, and instead, $5 \mathrm{mM}$ guanosine monophosphate was added. Transcribed RNAs were treated with RQ1 DNase (Promega) for $30 \mathrm{~min}$ at $37^{\circ} \mathrm{C}$ and then purified on $12 \%$ (flexizyme) or $8 \%$ (tRNA) polyacrylamide gels containing $6 \mathrm{M}$ urea.

\section{Acylation of $\boldsymbol{\mu h R N A}$ and tRNA}

${ }^{\mathrm{NO}}$ Gly, L- ${ }^{\mathrm{NO}} \mathrm{Ala}, \mathrm{D}-{ }^{\mathrm{NO}} \mathrm{Ala},{ }^{\mathrm{NO}} \mathrm{Aib},{ }^{\mathrm{NN}} \mathrm{MeGly}, \mathrm{L}-{ }^{\mathrm{NN}}$ Pro, D- ${ }^{\mathrm{NN}}$ Pro, D-Pro, L-Ala, D-Ala, D-Cys, D-Pro, and $\beta$-hGly were preactivated as DBE forms and L- ${ }^{\mathrm{NO}} \mathrm{Phe}, \mathrm{D}^{\mathrm{NO}}{ }^{\mathrm{Ph}} \mathrm{Ph}$, and ${ }^{\mathrm{ClAc}} \mathrm{D}-\mathrm{Tyr}$ as CME forms as previously described. ${ }^{1,2}{ }^{1} \mathrm{H}$ - and ${ }^{13} \mathrm{C}$-NMR spectra of activated $\alpha$-aminoxy and $\alpha$-hydrazino acids are shown in Supplementary Figure S7. These substrates were charged on $\mu \mathrm{hRNA}$ or tRNA using appropriate flexizymes (dFx for DBE or eFx for CME). $\mu \mathrm{hRNA}$ was purchased from Eurofin Genomics. Reaction conditions were $4^{\circ} \mathrm{C}$ for $2-72 \mathrm{~h}$ in a reaction mix containing $600 \mathrm{mM} \mathrm{MgCl} 2,20 \%$ DMSO, $25 \mu \mathrm{M}$ eFx or dFx, $25 \mu \mathrm{M} \mu \mathrm{hRNA}$ or tRNA, and $5 \mathrm{mM}$ activated amino acid. The $\mathrm{pH}$ of the reaction mixture was adjusted by $50 \mathrm{mM}$ HEPES-KOH $(\mathrm{pH}$ 7.5 or 8.0 ) or bicine- $\mathrm{KOH}(\mathrm{pH} 8.5$ or 9.0). Optimal reaction conditions are summarized in Supplementary Table S1. The resulting acyl-RNAs were recovered by ethanol precipitation and washed with $70 \%$ ethanol. Thirty-three pmol acyl- $\mu$ hRNA was analyzed on $20 \%$ polyacrylamide gels containing $6 \mathrm{M}$ urea at $4.3 \mathrm{pH}$ adjusted by $50 \mathrm{mM}$ sodium acetate $(\mathrm{pH} 4.3)$. Electrophoresis used $280 \mathrm{~V}$ for $5 \mathrm{~h}$, followed by ethidium bromide staining and detection using a Typhoon FLA 7000 (Cytiva).

\section{In vitro translation of model peptides}

Translation of model peptides $\mathrm{P} 1-\mathrm{P} 10$ was carried out at $37^{\circ} \mathrm{C}$ for $45 \mathrm{~min}$ in a custom-made FIT system containing the following components: $50 \mathrm{mM}$ HEPES-KOH (pH 7.6), $100 \mathrm{mM}$ potassium acetate, $12.3 \mathrm{mM}$ magnesium acetate, $2 \mathrm{mM}$ ATP, $2 \mathrm{mM} \mathrm{GTP,} 1 \mathrm{mM}$ CTP, $1 \mathrm{mM}$ UTP, $20 \mathrm{mM}$ creatine phosphate, $0.1 \mathrm{mM} 10$-formyl-5,6,7,8-tetrahydrofolic acid, $2 \mathrm{mM}$ spermidine, $1 \mathrm{mM}$ DTT, $1.5 \mathrm{mg} / \mathrm{mL} E$. coli total tRNA, $1.2 \mu \mathrm{M} E$. coli ribosome, $0.6 \mu \mathrm{M}$ methionyl-tRNA formyltransferase, $2.7 \mu \mathrm{M}$ IF 1, $3 \mu \mathrm{M}$ IF2, $1.5 \mu \mathrm{M}$ IF3, $0.1 \mu \mathrm{M}$ EF-G, $20 \mu \mathrm{M}$ EF-Tu/Ts, $0.25 \mu \mathrm{M}$ RF2, $0.17 \mu \mathrm{M}$ RF3, $0.5 \mu \mathrm{M}$ RRF, $4 \mu \mathrm{g} / \mathrm{mL}$ creatine kinase, $3 \mu \mathrm{g} / \mathrm{mL}$ myokinase, $0.1 \mu \mathrm{M}$ inorganic pyrophosphatase, $0.1 \mu \mathrm{M}$ nucleotide diphosphate kinase, $0.1 \mu \mathrm{M}$ T7 RNA polymerase, $0.13 \mu \mathrm{M}$ AspRS, $0.11 \mu \mathrm{M}$ LysRS, $0.03 \mu \mathrm{M}$ MetRS, $0.68 \mu \mathrm{M}$ PheRS, $0.02 \mu \mathrm{M}$ TyrRS, $0.09 \mu \mathrm{M}$ GlyRS, 0.5 mM Asp, 0.5 mM Lys, $0.5 \mathrm{mM}$ Met, $0.5 \mathrm{mM}$ Phe, $0.5 \mathrm{mM}$ Tyr, $0.5 \mathrm{mM}$ Gly, $40 \mu \mathrm{M}$ each pre-charged acyl-tRNAs, and $0.5 \mu \mathrm{M}$ DNA template. DNA templates used for translation were prepared by extension reactions using appropriate forward/reverse extension primer pairs, followed by PCR amplification using forward/reverse PCR primer pairs (see Supplementary Table S2 for the primer sequences). For translation of peptides P11-P16, $0.73 \mu \mathrm{M}$ AlaRS and 0.5 $\mathrm{mM}$ Ala were added to the above reaction mixture. For translation of macrocyclic peptides P15 and P16, 10-formyl-5,6,7,8-tetrahydrofolic acid, MetRS, and Met were omitted, and the concentration of ${ }^{\mathrm{ClAc}} \mathrm{D}-\mathrm{Ty}-\mathrm{R}-\mathrm{RNA}{ }^{\text {ini }}$ was $12.5 \mu \mathrm{M}$.

\section{MALDI-TOF mass spectrometry of model peptides}

The above translation reaction mixture was diluted with an equal volume of $2 \times$ HBS buffer [100 mM HEPES-KOH (pH 7.6), $300 \mathrm{mM} \mathrm{NaCl}$ ], mixed with $5 \mu \mathrm{L}$ ANTI-FLAG M2 affinity gel 
(Sigma), and incubated for $30 \mathrm{~min}$ at $25^{\circ} \mathrm{C}$. The amino acid sequence of the $\mathrm{C}$-terminal flag-tag of the model peptides is Asp-Tyr-Lys-Asp-Asp-Asp-Asp-Lys. The affinity gel was washed twice with $25 \mu \mathrm{L}$ of $1 \times$ HBS buffer [50 mM HEPES-KOH (pH 7.6), $150 \mathrm{mM} \mathrm{NaCl}$ ]. Peptides were then eluted from the gel with $30 \mu \mathrm{L}$ of $0.2 \%$ trifluoroacetic acid, desalted with SPE C-tip (Nikkyo Technos), and cocrystallized with $\alpha$-cyano-4-hydroxycinnamic acid. MALDI-TOF MS and MS/MS analyses used ultrafleXtreme (Bruker Daltonics) in reflector-positive mode (MS analysis) or LIFT-positive mode (MS/MS analysis). A peptide calibration standard II (Bruker Daltonics) was used for external mass calibration.

\section{Tricine SDS-PAGE of translated peptides}

Translation of model peptides was carried out for $30 \mathrm{~min}$ under the above reaction conditions with $0.05 \mathrm{mM}\left[{ }^{14} \mathrm{C}\right]$-Asp instead of $0.5 \mathrm{mM}$ cold Asp. Then, $2.5 \mu \mathrm{L}$ of stop solution $[0.9 \mathrm{M}$ Tris- $\mathrm{HCl}(\mathrm{pH} 8.45), 8 \%$ SDS, $30 \%$ glycerol, and $0.001 \%$ xylene cyanol] was added to $2.5 \mu \mathrm{L}$ reaction mix, and incubated at $95^{\circ} \mathrm{C}$ for $3 \mathrm{~min}$. The samples were subjected to $15 \%$ tricine SDS-PAGE and analyzed by autoradiography using a Typhoon FLA 7000 (Cytiva). Expression levels of peptides were normalized by the intensity of the $\left[{ }^{14} \mathrm{C}\right]$-Asp band.

\section{References for supplementary information}

(1) Murakami, H.; Ohta, A.; Ashigai, H.; Suga, H. A highly flexible tRNA acylation method for non-natural polypeptide synthesis. Nat. Methods 2006, 3, 357-359.

(2) Saito, H.; Kourouklis, D.; Suga, H. An in vitro evolved precursor tRNA with aminoacylation activity. EMBO J. 2001, 20, 1797-1806. 